\title{
In vivo MR spectroscopy reflects synapse density in a Huntington's disease mouse model
}

Nicole Zarate ${ }^{1 *}$, Katherine Gundry ${ }^{2}$, Dahyun $\mathrm{Yu}^{1}$, Jordan Casby ${ }^{3}$, Lynn E Eberly ${ }^{4,2}$, Gülin Öz ${ }^{2}$ and Rocio Gomez-Pastor ${ }^{1}$.

${ }^{1}$ Department of Neuroscience, Medical School, University of Minnesota, Minneapolis, MN, United States. ${ }^{2}$ Center for Magnetic Resonance Research, Department of Radiology, Medical School, University of Minnesota, Minneapolis, MN, United States. ${ }^{3}$ Department of Pharmacology, Medical School, University of Minnesota, Minneapolis, MN, United States. ${ }^{4}$ Division of Biostatistics, School of Public Health, University of Minnesota, Minneapolis, Minnesota.

*These authors contributed equally to the manuscript

ORCiD: Nicole Zarate (0000-0003-4839-7783), Katie Gundry (0000-0002-3333-1709), Dahyun Yu (0000-0002-3179-4080), Jordan Casby (0000-0002-5601-3906), Lynn Eberly (0000-0003-4763-330X), Gülin Öz (0000-0002-5769-183X), Rocio GomezPastor (0000-0003-1136-5462)

\pm Correspondence should be addressed to Rocio Gomez-Pastor, University of Minnesota, 321 Church St. SE, Jackson Hall Room 6-145, Minneapolis, MN 55455, rgomezpa@umn.edu

\section{Relevant conflicts of interest/Financial Disclosure: Nothing to report}

Funding Sources: This work was supported by the University of Minnesota Biomedical Research Awards for Interdisciplinary New Science (to R.G.P and G.O) and the National Institute of Health NINDS (R01 NS110694) (to R.G.P). The Center for Magnetic Resonance Research is supported by the National Institute of Biomedical Imaging and Bioengineering (NIBIB) grant P41 EB027061, the Institutional Center Cores for Advanced Neuroimaging award P30 NS076408 and the W.M. Keck Foundation.

Keywords: Huntington's disease, zQ175, synapse density, ${ }^{1} \mathrm{H}-\mathrm{MRS}, \mathrm{CK} 2$ alpha prime, neurochemicals, biomarkers. 


\section{Abstract}

Striatal medium spiny neurons are highly susceptible in Huntington's disease (HD), resulting in progressive synaptic perturbations that lead to neuronal dysfunction and death. Non-invasive imaging techniques, such as proton magnetic resonance spectroscopy ( $\left.{ }^{1} \mathrm{H}-\mathrm{MRS}\right)$, are used in $\mathrm{HD}$ mouse models and patients with $\mathrm{HD}$ to monitor neurochemical changes associated with neuronal health. However, the association between brain neurochemical alterations and synaptic dysregulation is unknown, limiting our ability to monitor potential treatments that may affect synapse function. We conducted in vivo longitudinal ${ }^{1} \mathrm{H}-\mathrm{MRS}$ in the striatum followed by ex-vivo analyses of excitatory synapse density of two synaptic circuits disrupted in HD, thalamo-striatal (T$\mathrm{S}$ ) and cortico-striatal (C-S) pathways, to assess the relationship between neurochemical alterations and changes in synapse density. We used the $z Q 175^{(\mathrm{Tg} / 0)} \mathrm{HD}$ mouse model as well as zQ175 mice lacking one allele of CK2 $\left.\alpha^{\prime}\left(\mathrm{zQ} 175^{(\mathrm{Tg} / 0)}\right) \mathrm{CK} 2 \alpha^{\prime(+/)}\right)$, a kinase previously shown to regulate synapse function in HD. Longitudinal analyses of excitatory synapse density showed early and sustained reduction in T-S synapses in zQ175 mice, preceding C-S synapse depletion, which was rescued in zQ175:CK2 $\alpha^{\prime(+/)}$. Changes in T-S and C-S synapses were accompanied by progressive alterations in numerous neurochemicals between WT and HD mice. Linear regression analyses showed C-S synapse number positively correlated with ${ }^{1} \mathrm{H}-\mathrm{MRS}$-measured levels of GABA while T-S synapse number positively correlated with levels of alanine, phosphoethanolamine and lactate, and negatively correlated with total creatine levels. These associations suggest that these neurochemical concentrations measured by ${ }^{1} \mathrm{H}$ MRS may facilitate monitoring circuit-specific synaptic dysfunction in the zQ175 mouse model and in other HD pre-clinical studies.

\section{Significance Statement}

The pathogenic events of many neurodegenerative diseases including HD are triggered by reductions in number of synapses. Therefore, in vivo measures that reflect synapse number represent a powerful tool to monitor synaptic changes in numerous brain disorders. In this study, we showed that non-invasive in vivo ${ }^{1} \mathrm{H}-\mathrm{MRS}$ reflects excitatory synapse number in the striatum of the ZQ175 mouse model of HD. The combination of longitudinal ${ }^{1} \mathrm{H}-\mathrm{MRS}$ and immunofluorescence synapse detection revealed that distinct neurochemical levels significantly correlated with different striatal glutamatergic synaptic input pathways, suggesting that ${ }^{1} \mathrm{H}-\mathrm{MRS}$ could distinguish circuit-dependent synapse changes in HD. These results provide potential neurochemical biomarkers to monitor synaptic changes in future pre-clinical trials with HD models. 


\section{INTRODUCTION}

Huntington's disease (HD) is an autosomal dominant, neurodegenerative disorder caused by expansion of a trinucleotide repeat (CAG) in exon 1 of the Huntingtin gene (HTT) (MacDonald et al., 1993). The HTT protein is prone to protein misfolding, and its aggregation preferentially affects medium spiny neurons (MSN) of the striatum, causing synaptic perturbations and neuronal death. HD is characterized by progressive motor, cognitive, and psychiatric deficits for which there is no effective therapies. To design therapies that effectively modify disease symptoms it is necessary to identify robust HD biomarkers able to objectively monitor cerebral pathology.

Mouse models of $\mathrm{HD}$ and patients with prodromal HD show perturbations in striatal synaptic stability and functional connectivity, respectively, before motor symptom onset or overt neuronal cell death (Raymond et al., 2011; Unschuld et al., 2012). Therefore, having the ability to monitor synaptic stability in the living brain could be a powerful tool to predict disease progression as well as determine the impact of potential therapeutic strategies on synaptic function. However, in vivo monitoring of synapses in the human brain is technically challenging. Recently developed Positron Emission Tomography (PET) radioligands targeting various synaptic vesicle proteins can be used to monitor synaptic density in both animals and humans (Finnema et al., 2016; Thomsen et al., 2021). However, the limited availability of these PET tracers and concerns about repeated radiation exposure provide motivation to assess alternative neuroimaging technologies to evaluate synapse density. Magnetic resonance (MR) methods like functional MR imaging (fMRI) and MR spectroscopy (MRS) overcome these concerns but have yet to be evaluated as markers of synaptic density.

MRS has emerged as a useful tool to evaluate neurochemical alterations in HD and other polyQ diseases (Öz et al., 2010; Sturrock et al., 2015; Öz, 2016; Joers et al., 2018). Studies in various mouse models of HD and in patients with HD have highlighted consistent alterations in key neurochemicals that can be associated with neurodegeneration, such as depletion of the neuronal integrity marker $\mathrm{N}$-acetylaspartate (NAA) or increased levels of the putative gliosis marker myo-inositol (Ins) (Tkác et al., 2007; Heikkinen et al., 2012; Sturrock et al., 2015; Peng et al., 2016). However, the underpinnings of the neurochemical changes that connect them with functional decline is still unknown, limiting our understanding of how potential treatments that may affect synapse function translate into alterations of brain metabolites. Previous studies in patients with different spinocerebellar ataxias (SCAs) presenting different degrees of synapse loss proposed that neurochemical alterations measured by MRS may reflect changes in synaptic function or density (Öz et al., 2011a; Joers et al., 2018). Consistently, a recent MRS study in aged zQ175 mice showed that key striatal neurochemical alterations paralleled changes in T-S synapses (Yu et al., 2020), highlighting the potential use of MRS as a tool to monitor synapse density. However, the relationship between neurochemical alterations and synaptic density has not been directly assessed thus far. 
In the present study we conducted in vivo longitudinal high field proton $\left({ }^{1} \mathrm{H}\right) \mathrm{MRS}$ in the striatum of the heterozygous ZQ175 HD mouse model followed by ex-vivo analyses of excitatory synapse densities of two major, differentially altered striatal synaptic circuits in HD; cortico-striatal (C-S) and thalamo-striatal (T-S). We also studied ZQ175 mice lacking one allele of CK2 $\alpha$, a kinase involved in synapse stability in HD, the haploinsufficiency of which differentially altered T-S and C-S circuitry and ameliorated long-term HD-like symptoms (Gomez-Pastor et al., 2017; Yu et al., 2020). We found that T-S synaptic density was significantly correlated with alterations in alanine (Ala), lactate (Lac), phosphoethanolamine (PE), and total creatine (tCr) while C-S synapse number significantly correlated with gamma-aminobutyric acid (GABA). We propose that GABA, Ala, Lac, PE, and tCr alterations could be used as surrogate biomarkers to monitor circuit-dependent synapse dysfunction during HD in zQ175 mice. Furthermore, these results support using MRS as a technique in future HD pre-clinical studies to monitor treatment efficacy in altering excitatory synaptic function in the striatum.

\section{METHODS}

\section{Experimental Design}

A cohort of mice (WT $n=13,8$ females, 5 males; $z Q 175 n=16,7$ females, 9 males; and zQ175:CK2 $\alpha^{\prime(+)} \mathrm{n}=16,11$ females, 5 males) were scanned at 3 months of age using a 9.4T scanner, after which a subset of the animals ( $n=4$ per genotype) were sacrificed for synapse density analyses ( $n=3$ per genotype were used). One additional zQ175:CK2 $\alpha^{\prime(+)}$ mouse was added to the cohort after the 3 months scan. Remaining animals were aged to 6 months at which time they were again scanned (WT $n=9,7$ females, 2 males; zQ175 n=12, 5 females, 7 males; and zQ175:CK2 $\alpha^{\prime(+/)} n=13,9$ females, 4 males), and another subset ( $n=4$ per genotype) sacrificed for synapse density analyses. Two zQ175:CK2 $\alpha^{\prime(+)}$ mice were harvested prior to being scanned at 12 months due to health issues. The remaining animals (WT $n=5$ ( 3 females, 2 males), zQ175 n=8 (4 females, 4 males), and zQ175:CK2 $\alpha^{(+/-)} n=7$ (4 females, 3 males) were scanned at 12 months followed by striatal synapse density analyses (only $n=3$ (2 females, 1 male) were used for zQ175:CK2 $\alpha^{\text {(+/-) }}$ synapse analysis). CK2 $\alpha^{(+/-)}$control mice were not included in the experimental design since they did not show significant changes in either T-S or C-S circuits compared to WT mice (Gomez-Pastor et al., 2017). We selected these three time points based on progression of motor symptoms (Heikkinen et al., 2012; Menalled et al., 2012): 3 months (pre-symptomatic), 6 months (early symptomatic) and 12 months (symptomatic). Longitudinal neuroimaging provided information for how neurochemical levels changed within individual mice over time. A diagram illustrating the experimental design is shown in Fig. 1.

\section{Animal Preparation for and Monitoring during MR Scanning}

All experiments were performed according to procedures approved by the University of Minnesota Institutional Animal Care and Use Committee. Animals were induced with 3\% isoflurane in a $1: 1$ mixture of $\mathrm{O}_{2}: \mathrm{N}_{2} \mathrm{O}$. Mice were secured in a custom-built mouse 
holder and physiological status was monitored (SA Instruments) and recorded. Anesthesia was maintained with $1.5-2 \%$ isoflurane to achieve a respiration rate of 70 100 breaths per minute. Body temperature was maintained at $36-37^{\circ} \mathrm{C}$ with a circulating warm water system and a heating fan controlled by feedback received from a fiber-optic rectal thermometer. The scan session was approximately 50 minutes for each animal.

\section{MR Protocol}

All experiments were performed on a $9.4 \mathrm{~T} / 31 \mathrm{~cm}$ scanner (Agilent), as described previously (Öz et al., 2015; Friedrich et al., 2018). A quadrature surface radio frequency (RF) coil with two geometrically decoupled single turn coils (14 $\mathrm{mm}$ diameter) was used as the MR transceiver. Following positioning of the mouse in the magnet, coronal and sagittal multislice images were obtained using a rapid acquisition with relaxation enhancement (RARE) sequence (Hennig et al., 1986) [repetition time (TR)= $4 \mathrm{~s}$, echo train length $=8$, echo time $(T E)=60 \mathrm{~ms}$, slice thickness $=1 \mathrm{~mm}, 7$ slices]. The volume of interest (VOI) was centered on the striatum $\left(8.2 \mu \mathrm{l}, 1.7 \times 2.0 \times 2.4 \mathrm{~mm}^{3}\right)$. All first- and second-order shims were adjusted using FASTMAP with echo-planar readout (Gruetter and Tkác, 2000). Localized ${ }^{1} \mathrm{H}$ MR spectra were acquired with a short-echo localization by adiabatic selective refocusing (LASER) sequence [TE= $15 \mathrm{~ms}$, TR= $5 \mathrm{~s}, 256$ transients] (Garwood and DelaBarre, 2001) combined with VAPOR (variable power RF pulses with optimized relaxation delays) water suppression (Tkác et al., 1999). Spectra were saved as single scans. Unsuppressed water spectra were acquired from the same VOI for metabolite quantification.

\section{Metabolite quantification}

Single shots were eddy current, frequency, and phase corrected using MRspa software (http://www.cmrr.umn.edu/downloads/mrspa/) before averaging. The contributions of individual metabolites to the averaged spectra were quantified using LCModel (Provencher, 1993) as described previously (Friedrich et al., 2018). The following metabolites were included in the basis set: alanine (Ala), ascorbate/vitamin C (Asc), aspartate, glycerophosphocholine (GPC), phosphocholine (PCho), creatine ( $\mathrm{Cr}$ ), phosphocreatine (PCr), gamma-aminobutyric acid (GABA), glucose (Glc), glutamine (Gln), glutamate (Glu), glutathione, glycine, myo-inositol (Ins), lactate (Lac), $N$ acetylaspartate (NAA), $N$-acetylaspartylglutamate (NAAG), phosphoethanolamine (PE), taurine (Tau), and macromolecules (MM). The MM spectra were experimentally obtained from a VOI that covered the striatum using an inversion recovery technique [VOI $=4.7 \times 2.1 \times 2.7 \mathrm{~mm}^{3}, \mathrm{TE}=15 \mathrm{~ms}, \mathrm{TR}=2.0 \mathrm{~s}$, inversion time $(\mathrm{TIR})=675 \mathrm{~ms}, 400$ transients, $\mathrm{N}=2$ ]. The model metabolite spectra were generated using density matrix simulations (Govindaraju et al., 2000) with the MATLAB software (MathWorks) based on previously reported chemical shifts and coupling constants (Govindaraju et al., 2000; Tkác, 2008). Concentrations with mean Cramér-Rao lower bounds (CRLB) $\leq 20 \%$ in any of the 3 groups were reported (Friedrich et al., 2018). If the correlation between two 
metabolites was consistently high (correlation coefficient $r<-0.7$ ), their sum was reported rather than the individual values (Friedrich et al., 2018), this was the case for total NAA (tNAA= NAA+NAAG), total $\mathrm{Cr}(\mathrm{tCr}=\mathrm{Cr}+\mathrm{PCr})$ and total $\mathrm{Cho}(\mathrm{tCho}=$ GPC+PCho). In addition, Glc + Tau was reported in addition to the separate Glc and Tau concentrations because the individual concentrations did not always meet the mean CRLB $\leq 20 \%$ criterion and Glc and Tau have similar spectral patterns.

\section{Synapse density quantification}

Two to three independent coronal brain sections were used for each mouse, containing the dorsal striatum (bregma 0.5-1.1 mm) and were stained with presynaptic VGlut1 (Millipore AB5905, 1:500) or VGlut2 (Millipore AB2251-I1:1000) and postsynaptic PSD95 (Thermofisher 51-6900, 1:500) markers as described previously (Ippolito and Eroglu, 2010; Mckinstry et al., 2014; Gomez-Pastor et al., 2017). Secondary antibodies used were goat anti-guinea pig Alexa 488 (VGlut1/2, Invitrogen A-11073, 1:200) and goat anti-rabbit Alex 594 (PSD-95, Invitrogen A-11012, 1:200). At least three mice for each genotype; WT, zQ175 and zQ175:CK2 $\alpha^{\prime(+/)}$ were evaluated. The confocal scans (optical section depth $0.34 \mathrm{~mm}, 15$ sections per scan) of the synaptic zone in the dorsal striatum were performed at 60X magnification on an Olympus FV1000 confocal laserscanning microscope. Maximum projections of three consecutive optical sections were generated. The Puncta Analyzer Plugin for ImageJ was used to count co-localized synaptic puncta in a blinded fashion. This assay takes the advantage of the fact that presynaptic and postsynaptic proteins reside in separate cell compartments (axons and dendrites, respectively), and they would appear to co-localize at synapses because of their close proximity. The number of animals used in this analysis was 3 per genotype (3 month timepoint), 4 per genotype (6 month timepoint), and 5-6 WT, 7-8 zQ175, and 3 zQ175:CK2 $\alpha^{(+/-)}$(12 month timepoint).

\section{Data Analysis}

All statistics were conducted using GraphPad Prism 9 software. Group averages between genotypes were compared at each time point using one-way ANOVA for MRS and synapse densities with Tukey's post-hoc test to adjust for multiple comparisons. Significant group differences for synapse density were calculated using n=6-9 images per animal, 3 animals minimum per genotype, resulting in a minimum of 18 data points per genotype for statistical analyses. Only averages for each mouse are shown. Pearson correlation analyses were run separately for each neurochemical against synapse number. Holm-Šídák adjustment of correlation p-values was used to correct for the multiple testing of the many neurochemicals together with metabolite sums and metabolite ratio. A full report of results for MRS ANOVAs are in Table 1, with synapse analyses in Table 2, and correlation analyses in Table 3. Fisher's exact test was conducted to evaluate sex differences for all metabolites (none were found). Error bars always represent mean \pm standard deviation (SD). 


\section{RESULTS}

\section{Longitudinal in vivo ${ }^{1} \mathrm{H}-M R S$ captures genotype and age-specific striatal neurochemical changes in the ZQ175 HD mouse model}

MRS studies have been widely applied to evaluate neurodegeneration in several mouse models of HD and patients with HD (Tkác et al., 2007; Sturrock et al., 2010, 2015; Heikkinen et al., 2012; Peng et al., 2016). The use of mouse models allows for parallel characterization of neurochemical concentrations and neuropathological features, an essential aspect of understanding how different neurochemical abnormalities relate to pathology. We chose the heterozygous knock-in zQ175 HD mouse model (zQ175 ${ }^{\mathrm{Tg} / 0}$ ) for its slow disease progression and its ability to recapitulate multiple HD-like features observed in patients with HD, such as HTT aggregation, progressive synaptic deficits, transcriptional dysregulation, gliosis, weight loss, and motor and cognitive impairment (Heikkinen et al., 2012; Menalled et al., 2012; Gomez-Pastor et al., 2017).

We utilized in vivo ${ }^{1} \mathrm{H}-\mathrm{MRS}$ to measure neurochemicals in the striatum of WT, zQ175, and $z Q 175: C K 2 \alpha^{\prime(+-)}$ mice in a longitudinal manner and in parallel with ex vivo synapse density analyses to obtain simultaneous information for potential neurochemical and synapse alterations across different genotypes and time points (Fig. 1). A total of 19 neurochemicals, including 4 sums, were quantified reliably in the dorsolateral striatum (Table 1). In addition, tNAA/tCr ratio was computed as it is frequently utilized as a marker of neuronal viability and to enable comparison of the current results with prior literature. Seven neurochemicals (Ala, Asc, Gln, Ins, PE, tCho, and tCr) and tNAA/tCr showed significant group differences primarily at 6 and 12 months of age (Fig. 2). Ala, Asc, Ins, and PE (Fig. 2A, B, C, D) showed a decrease with age in WT mice while GIn (Fig. 2E) increased. Similar age-dependent alterations in brain neurochemicals have also been reported in C57BL/6 mice and in human studies comparing young and middle-aged subjects (Grachev and Apkarian, 2001; Duarte et al., 2014), indicating these alterations are common brain modifications during aging.

The levels of several neurochemicals in zQ175 mice significantly differed compared to WT at multiple time points. GIn was significantly higher in zQ175 vs. WT starting at 3 months and increased even further at 6 and 12 months (Fig. 2C). tCr was significantly higher and tCho lower in ZQ175 mice vs. WT at 6 and 12 months (Fig. 2F, G) coinciding with previously reported worsening motor and cognitive symptoms. On the other hand, no significant differences in tNAA were observed between WT and ZQ175 mice while a higher Ins level in zQ175 mice reached statistical significance only at 6 months (Fig.

2D, Table 1), recapitulating what was previously reported for this mouse model (Heikkinen et al., 2012). When tNAA was referenced to $\mathrm{tCr}$, which is often used as an internal concentration reference, we found a significantly lower (tNAA/tCr) ratio in zQ175 vs. WT mice at 6 and 12 months (Fig. 2H). This ratio was relatively stable in WT mice over time, but it showed an age-dependent decrease in zQ175 mice. However, this alteration most likely reflects changes in tCr. Lower NAA and higher Ins, which are considered markers of neurodegeneration, were previously reported in more severe HD mouse models such as the R6/2 (12 weeks) (Tkác et al., 2007), homozygous zQ175(Tg/Tg) $(12$ months) (Peng et al., 2016) and in older zQ175 Tg/0 (22 months) (Tkác 
et al., 2007; Heikkinen et al., 2012; Peng et al., 2016; Yu et al., 2020). Therefore, these data suggests that tNAA and Ins may reflect substantial neurodegeneration in advanced disease. On the other hand, changes in GIn, tCr, tCho and tNAA/tCr in HD mice coincided with symptom onset and progression for this HD mouse model.

Given the previously described positive effects of CK2 $\alpha$ ' haploinsufficiency in ameliorating HD-like symptoms (Gomez-Pastor et al., 2017; Yu et al., 2020), we expected to see a number of neurochemicals that were significantly different between zQ175 and zQ175:CK2 $\alpha^{\prime+/-)}$ mice. Interestingly, we only observed significant differences between these two genotypes at 3 months for Gln (Fig. 2E), while no significant differences were observed between WT and zQ175:CK2 $\alpha^{\prime(+/)}$ mice at the later time points, indicating that the characteristic increase in GIn in zQ175 could be delayed as a consequence of manipulating CK2 $\alpha^{\prime}$ levels. zQ175:CK2 $\alpha^{\prime(+-)}$ mice have previously shown decreased HTT aggregation in the striatum, increased excitatory synaptic transmission and improved motor coordination compared to zQ175 (Yu et al., 2020). The early lower GIn level in zQ175:CK2 $\alpha^{\prime(+-)}$ vs. zQ175 mice may therefore reflect those pathological features.

\section{Loss of thalamo-striatal excitatory synapses precedes cortico-striatal synapse loss and is sustained over time}

MSNs receive excitatory glutamatergic input from the cortex and intralaminar nuclei of the thalamus and both D1 (direct pathway) and D2-type MSNs (indirect pathway) rely equally on these excitatory inputs (Smith et al., 2009; Huerta-Ocampo et al., 2014). Dysfunction in the cortico-striatal (C-S) pathway has been widely reported in HD, showing disruptions in this circuitry occur prior to MSN death thereby suggesting they are the leading cause for neuronal dysfunction (Cepeda et al., 2007; Raymond et al., 2011; Unschuld et al., 2012). However, recent studies in cell and mouse models of HD showed that thalamic input is also disrupted in HD and occurs before C-S circuit pathology or onset of motor symptoms (Cepeda et al., 2007; Mckinstry et al., 2014; Kolodziejczyk and Raymond, 2016; Gomez-Pastor et al., 2017), indicating that the thalamo-striatal (T-S) excitatory circuit may play a more prominent role in early HD pathogenesis than previously considered.

To study whether specific neurochemical alterations relate to changes in synapse density, we first determined changes in excitatory synapse density in WT, zQ175, and ZQ175:CK2 $\alpha^{\prime(+/)}$ mice, looking at both C-S and T-S circuitries during disease progression (Fig. 3A). Synapse density was quantified using immunofluorescent colocalization of the presynaptic markers VGlut1 (Vesicular glutamate transporter 1: specific marker for cortical input) and VGlut2 (Vesicular glutamate transporter 2: specific marker for thalamic input) (Fujiyama et al., 2004; Huerta-Ocampo et al., 2014) and the post-synaptic marker PSD-95 (post-synaptic density protein 95) in the dorsal striatum of 3, 6, and 12 month old animals (Fig. 3B). C-S synapses were initially higher in $\mathrm{zQ} 175: \mathrm{CK} 2 \alpha^{\prime(+-)}$ mice compared to WT, however by 6 months this trend had reversed and by 12 months had become significantly lower in both zQ175 and zQ175:CK2a'(+/-) 
mice compared to WT (Fig. 3C, Table 2). In contrast, levels of T-S synapses in zQ175 mice were significantly reduced compared to WT at all 3 time points while these decreases were significantly rescued in zQ175:CK2 $\alpha^{\prime(+/)}$ mice at 3 and 6 months (Fig. 3D, Table 2). These results validated previous observations in $z Q 175: C K 2 \alpha^{\prime(+/)}$ mice, showing ameliorated T-S synapse loss and long-term HD-like symptoms with limited impact on C-S synapse density (Gomez-Pastor et al., 2017). The lack of statistically significant rescue at 12 months between zQ175 and zQ175:CK2 $\alpha^{\prime(+/)}$ suggests that CK2 $\alpha$ ' haploinsufficiency delays the onset of T-S synapse loss but does not prevent progression. Taken together, these data further demonstrate that there are circuitspecific changes in striatal excitatory synapse dysfunction in HD that, in the T-S pathway, are in part ameliorated by reducing levels of CK2 $\alpha$ '.

\section{Changes in striatal neurochemical levels correlate with circuit-dependent changes in synapse density}

Given the alterations in neurochemical levels and changes in excitatory synapse densities between the different genotypes, we wanted to determine if these two measures were significantly correlated with each other, potentially allowing us to identify surrogate biomarkers for synapse loss in HD. We performed correlation analyses across all mice used in this study $(n=36)$. Synapse number for each mouse analyzed at one of three time points (3, 6 and 12 months) was used as the predictor variable in the analysis and neurochemical levels at the same time points as the response variable (Fig. 4, Table 3). Regressions were run separately to examine each synaptic circuit, T-S and C-S, and their correlation with each neurochemical level. When analyzed in this manner, we found a significant positive correlation $(p<0.05)$ between $C-S$ synapse number and GABA (Fig. 4A, B). Statistical significance of this correlation was maintained even after conservative multiple testing adjustment of $p$-values across all the metabolites. GIn and tCho had statistically significant un-adjusted p-values but only modestly sized correlations. GABA is known for its role as the primary inhibitory neurotransmitter in the adult brain and dysfunction in GABAergic signaling has been implicated in HD mouse models as well as patients with HD (Hsu et al., 2018). It is important to note that despite the positive correlation between GABA and C-S synapse number, we did not observe a reduction in GABA levels in the two HD models relative to WT (Table 1). This is consistent with previous reports that have used ${ }^{1} \mathrm{H}-\mathrm{MRS}$ in $\mathrm{zQ} 175$ and R6/2 mouse models (Tkác et al., 2007; Heikkinen et al., 2012). A potential explanation is that ANOVAs of the neurochemical concentrations are based on the average concentration across multiple mice within the same genotype and the variability within groups overwhelmed the group differences across genotypes. However, the correlation analyses are conducted by plotting individual concentrations for each analyzed animal and their corresponding C-S synapse number. This suggests that individual levels of GABA are inherently associated with the C-S synapse density regardless of the genotype.

In T-S circuitry, we found Ala, Lac, PE had positive correlations of a meaningful magnitude (Table 3, Fig 4C-G). tCr and tNAA/tCr had slightly weaker correlation 
values. Conservative multiple testing adjustment of $p$-values across all the metabolites did not maintain their statistical significance despite the global effect being significant. This could be due to the conservativism of the multiple testing adjustment, the high number of MRS measurements being tested $(n=20)$, and the relatively small sample size which together may result in rejecting significant associations that in reality are meaningful. Among the neurochemicals that showed significant correlations with synapse density based on unadjusted p-values, Lac concentration did not show a significant alteration across the different genotypes and Ala was significantly altered only at 6 months between WT and zQ175 (Table 1). However, both Lac and Ala presented a trend towards lower levels in ZQ175 compared with WT mice and were partially rescued in $z Q 175: C K 2 \alpha^{\prime+/-)}($ Table 1). Similar trends for Ala and Lac were shown in symptomatic R6/2 mice (Tkác et al., 2007). PE was significantly lower in both zQ175 and zQ175:CK2 $\alpha^{\prime(+/)}$ than WT at 6 months (Fig. 2C, Table 1). tCr showed an increasing trend over time in both $z Q 175$ and $z Q 175: C K 2 \alpha^{\prime(+/)}$ and was higher than WT at 6 and 12 months (Fig. 2F). These data indicate that by combining the levels of GABA, Ala, Lac, PE, and tCr, it could be possible to evaluate circuit-dependent synapse content during HD.

\section{Discussion}

In this first direct assessment of the longitudinal association between neurochemical abnormalities and excitatory synapse density in the mouse brain we show that distinct neurochemical levels significantly correlate with different striatal glutamatergic synaptic input pathways in the zQ175 model, suggesting that ${ }^{1} \mathrm{H}-\mathrm{MRS}$ may distinguish circuitdependent synapse changes in HD.

The current immunofluorescence data confirmed and expanded previous observations regarding changes in T-S and C-S synapse density in ZQ175 and other mouse models (Raymond et al., 2011; Deng et al., 2014; Mckinstry et al., 2014; Gomez-Pastor et al., 2017) and showed that C-S synapse depletion occurs at advanced disease stages in fully symptomatic animals, while T-S synapse depletion occurs earlier. We also showed that reducing levels of CK2 $\alpha$, a kinase previously associated with the dysregulation of synaptic activity in HD (Gomez-Pastor et al., 2017; Yu et al., 2020), prevented loss of TS synapses without altering C-S synapse density, supporting previous data in younger mice (Gomez-Pastor et al., 2017). In older mice (12 months), reduction of CK2a' did not completely suppress T-S synapse loss but rather delayed its onset. It is unknown how CK2 $\alpha$ ' haploinsufficiency selectively improved T-S synapse loss during early stages of disease, although this could be related to a different regulatory role of CK2 $\alpha$ ' between D1 and D2-MSNs, the latter being preferentially altered in HD (Reiner et al., 1988; Rebholz et al., 2013). Further studies are warranted to uncover the specific role of CK2 $\alpha^{\prime}$ in the differential regulation of T-S and C-S synapses.

${ }^{1} \mathrm{H}-\mathrm{MRS}$ in patients with SCAs with different degrees of synapse loss showed a similar ranking in the severity of neurochemical alterations suggesting that neurochemical abnormalities across different SCAs, and perhaps other neurodegenerative diseases, 
may reflect abnormalities in synaptic function or density (Öz et al., 2011b; Joers et al., 2018). Immunohistochemical analyses for synaptic vesicles (SV2A) combined with antemortem ${ }^{1} \mathrm{H}-\mathrm{MRS}$ in brains from patients with Alzheimer's disease (AD) showed decreased tNAA/tCr was associated with loss of synapses and early Tau pathology while increased Ins/tCr was associated with the occurrence of amyloid plaques in AD (Murray et al., 2014). Furthermore, a recent study in an AD mouse model with engrafted WT neural stem cells in the hippocampus showed changes in NAA and Glu that paralleled altered expression of synaptic proteins like PSD-95 and synaptophysin, and number of synapses (measured by electron microscopy) (Zhang et al., 2017). In a different study, ${ }^{1} \mathrm{H}-\mathrm{MRS}$ and synaptic protein analyses by immunoblotting in mice fed with a high fat diet showed increases in $\mathrm{tCr}$ and GIn that paralleled decreased synaptic proteins PSD-95 and VGlut1 (Lizarbe et al., 2018). Although correlations between neurochemicals and synapse numbers were not investigated with data collected in the same brains at the same time point/age in these prior studies, these reports established a plausible connection between key neurochemical alterations and synapse density.

In HD, ${ }^{1} \mathrm{H}-\mathrm{MRS}$ analyses have also highlighted tNAA, Ins and $\mathrm{tCr}$ as biomarkers of neurodegeneration (Tkác et al., 2007; Sturrock et al., 2010, 2015; Heikkinen et al., 2012; Peng et al., 2016). However, the differences between HD mouse models and patients regarding alterations of these specific neurochemicals, necessitate a careful analysis and validation of their potential relevance in defining synapse loss. In presymptomatic patients with HD, tNAA is lower than unaffected individuals and decreases further during disease progression, correlating with impaired motor and cognitive function (Leavitt et al., 2011). However, changes in tNAA are mostly observed only in symptomatic HD mice. Similarly, increased Ins was only observed in symptomatic HD mice (Tkác et al., 2007; Heikkinen et al., 2012; Yu et al., 2020). Therefore, tNAA and Ins seem to represent biomarkers for advanced disease in HD mouse models. This is supported by longitudinal MRS performed at 7T in zQ175, showing no significant alterations in tNAA or Ins up to 12 months (Heikkinen et al., 2012). Our current data at 9.4T validated these results for tNAA up to 12 months, but we previously reported changes in older (22 months) ZQ175 mice (Yu et al., 2020). In addition, we found higher Ins in zQ175 vs. WT mice, which was significant at 6 months. Discrepancies between $\mathrm{HD}$ mouse models and patients were also reported for $\mathrm{tCr}$ (Sánchez-Pernaute et al., 1999; Sturrock et al., 2015; Adanyeguh et al., 2018). We confirmed an age-dependent increase in tCr in zQ175 and reported additional alterations in Gln, tCho and tNAA/tCr between WT and zQ175. These changes were not attributed to ventricular enlargement or large brain volume alterations between $Z$ Q175 and WT mice since no differences in these parameters were observed even in older mice (Yu et al., 2020). Also, if CSF contribution to the MRS voxel was significantly higher in HD vs. WT mice, we would expect a lowering of all metabolite levels in HD vs. WT, however some metabolites are higher (e.g. tCr, GIn, Ins) while others (tCho, PE, Ala) are lower in HD vs. WT. We conclude that $\mathrm{GIn}$, tCr, tCho and tNAA/tCr represent biomarkers that monitor disease progression in zQ175 mice better than tNAA or Ins.

Among all tested neurochemicals, we only detected a significant alteration in GIn when comparing zQ175 and zQ175:CK2 $\alpha^{\prime(+/)}$. This was unexpected due to this latest model showing improvements in several HD-like phenotypes including decreased HTT 
aggregation and astrogliosis, increased synaptic density and neuronal excitability, and improved motor coordination (Gomez-Pastor et al., 2017; Yu et al., 2020). GIn levels increased over time in all mice but were significantly higher in zQ175 compared to WT starting at 3 months, consistent with a previously reported excitotoxic state (Fan and Raymond, 2007; Hassel et al., 2008). Analyses in R6/2 mice showed early increases in Gln levels (Tkác et al., 2007). Increased Gln has been associated with an imbalance in Glu-GIn cycling between neurons and astrocytes, reflecting compromised glutamatergic neurotransmission (Liévens et al., 2001; Behrens et al., 2002). Notably, no significant difference in GIn levels were found between WT and zQ175:CK2 $\alpha^{\prime(+)}$. Therefore, it is reasonable to hypothesize that early decreased GIn in zQ175:CK2 $\alpha^{(+/-)}$vs. zQ175 could be associated with improved neuronal excitability. In support of this hypothesis, zQ175:CK2 $\alpha^{\prime+/-)}$ previously showed improved AMPA-mediated excitatory transmission in the dorsolateral striatum when compared to zQ175 (Yu et al., 2020).

Correlation analyses revealed a direct association between changes in specific neurochemicals and circuit-dependent synapse changes. We found a significant positive correlation between levels of GABA and C-S synapse density. Deficiency in GABA signaling was associated with HD and other movement disorders (Hsu et al., 2018). Lower GABA content in the dorsal striatum and cortex was reported in postmortem brain from patients with HD (Spokes et al., 1980). Metabolic profiling using ${ }^{13} \mathrm{C}$ labeling and mass spectrometry in symptomatic R6/2 mice also showed decreased GABA synthesis (Skotte et al., 2018). However, ${ }^{1} \mathrm{H}-\mathrm{MRS}$ did not reveal changes in GABA levels in R6/2 compared with WT (Tkác et al., 2007). We also did not detect significant differences in GABA between WT and zQ175. The discrepancy between the lack of overall alterations in GABA and its correlation with $\mathrm{C}-\mathrm{S}$ synapse density could be explained by individual levels of GABA being inherently associated with C-S synapse density regardless of genotype. On the other hand, we observed significant correlations between T-S synapse density and Ala, Lac, PE, and tCr. Ala and other neutral amino acids are low in plasma from patients with HD, which correlates with symptom status (Reilmann et al., 1995; Underwood et al., 2006). Lac is an end-product of glycolysis associated with glutamatergic synaptic activity (Solís-Maldonado et al., 2018). ${ }^{1} \mathrm{H}-\mathrm{MRS}$ Lac changes in patients with HD is controversial (Adanyeguh et al., 2018) but studies using ${ }^{13} \mathrm{C}$-Lac showed decreased Lac uptake in HD cells (Solís-Maldonado et al., 2018). Although not statistically significant, we observed an overall decrease of Ala and Lac in zQ175 relative to WT that was partially rescued in zQ175:CK2 $\alpha^{\prime+/-)}$. Alterations in PE and $\mathrm{tCr}$, which are connected with neuronal integrity and function, have been consistently reported in mouse models and patients with HD and are associated with disease burden (Tkác et al., 2007; Sturrock et al., 2010, 2015; Adanyeguh et al., 2018). tCr increased over time in zQ175 and zQ175:CK2 $\alpha^{(+/-)}$compared with WT and significantly correlated with T-S synapse density. Our data suggest that a combination of the levels of GABA, Ala, Lac, PE, and $\mathrm{tCr}$ could be used to assess levels of striatal glutamatergic synapses in HD.

Overall, this study demonstrates the feasibility of using ${ }^{1} \mathrm{H}-\mathrm{MRS}$ to potentially monitor synaptic changes in vivo during HD progression. A limitation of our study is the difference between the MRS volume, and the area covered in synapse density analyses. The correlation analyses could be improved in future studies by reducing the 
MRS VOI size and distributing the tissue sampling areas for immunohistochemistry further within the MRS VOI. In addition, while significant correlations between neurochemicals and synapse loss were found, we cannot discard these associations as being influenced by other neuropathological features. Therefore, further studies are needed to corroborate these findings in alternative models of HD and other neurodegenerative diseases to evaluate specific neurochemical biomarkers as a tool to monitor synaptic changes in future pre-clinical trials with HD models.

Acknowledgements: We thank Dr. Dinesh Deelchand for guidance in data analysis and assistance in LCModel basis set generation.

Authors' Roles: R.G.P. and G. O. obtained funding for this study and designed the experiments. N.Z., K.G., J.C., and D.Y. performed the experiments. N.Z., K.G., J.C., and D.Y. prepared and analyzed the data. G.O. supervised the MRS data acquisition and analysis. R.G.P. supervised the ex vivo tissue collection and synapse analyses. L.E. supervised the statistical analyses. N.Z. and R.G.P. wrote the first draft of the manuscript and all authors edited subsequent versions and approved the final version of the manuscript.

Financial Disclosure: Nothing to report.

\section{Figure and Table legends}

Figure 1. Diagram of experimental design and timeline. A) Genotypes and number of animals used for each analysis are annotated. A cohort of WT, zQ175 and zQ175:CK2 $\alpha^{\prime(+/)}$ mice were scanned longitudinally on a 9.4T magnet (MRS) and a subset of mice were sacrificed for synapse density analyses by immunohistochemistry at each time point. B) Diagrams indicate the brain region covered by MRS and synapse analysis. Yellow box indicates voxel range (Volume $=8.2 \mu \mathrm{l}$ ), blue box indicates synapse density ROI within the voxel range. Synapse density was analyzed as described in the Methods and Materials section by conducting PSD-95 and VGlut1 or VGlut2 co-localization analyses from at least $n=6-9$ images corresponding to $n=3$ coronal sections. Graphics were created with Biorender.com C) Localized proton MR spectra measured from the mouse dorsolateral striatum in WT, zQ175(Tg/0) and zQ175(Tg/0):CK2 $\alpha^{(+/-)}$mice at 3, 6, and 12 months old. The volume of interest is shown on T2-weighted images and alterations in neurochemicals visible in the spectra are shown.

Figure 2. Age and genotype-dependent neurochemical alterations in the mouse dorsolateral striatum. Longitudinal metabolite profile in WT, zQ175, and ZQ175:CK2 $\alpha^{\prime(+)}$ mice. Only neurochemicals that showed significant differences between genotypes are shown (see Table 1). Error bars represent mean \pm SD. Oneway ANOVA with Tukey's post-hoc test. * $p<0.05$ WT vs. $z Q 175, \# p<0.05$ WT vs.

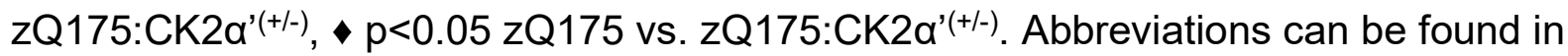


the methods section. For 3 month WT $n=13, z Q 175 n=16, z Q 175: C K 2 \alpha^{\prime(+-)} n=16.6$ month WT $n=9, z Q 175 n=12, z Q 175: C K 2 \alpha^{(+/-)} n=13.12$ month WT $n=5, z Q 175 n=8$, zQ175:CK2a'(+/-) n=7.

Figure 3. Onset of thalamo-striatal (T-S) synapse loss precedes cortico-striatal synapse deficits in zQ175 mice and it is delayed in zQ175:CK2 $\alpha^{\text {(+/-) }}$ mice. A) Diagram of the striatal excitatory circuitry. B) Colocalization (white arrows) of presynaptic (VGlut1/2) and post-synaptic (PSD-95) markers in WT, zQ175, and zQ175:CK2 $\alpha^{\prime(+/)}$ mice. Representative images from 6 months. Scale bar: $5 \mu \mathrm{m}$. C-D) Quantification of C-S and T-S synapses respectively at 3, 6, and 12 months old between genotypes. At each time point, WT n=3-6, zQ175 n= 3-8, zQ175:CK2a(+/-) $n=3-4$. Significant group differences were calculated using $n=6-9$ images per animal resulting in a minimum of 18 data points per genotype for statistical analyses. Only averages for each individual mouse are shown. Error bars represent mean \pm SD. ${ }^{*} p<0.05,{ }^{* *} p<0.01,{ }^{* * *} p<0.001,{ }^{* * *} p<0.0001$, one-way ANOVA with Tukey's post-hoc test.

Figure 4. Selective neurochemical alterations differentially correlate with striatal synaptic circuits. A) Illustration of $\mathrm{C}-\mathrm{S}$ correlation with metabolites (GABA). B) Correlation analysis of C-S synapse density vs. GABA where raw synapse numbers are plotted against corresponding neurochemical levels. C) Illustration T-S correlation with metabolites. D-G) Correlation analysis of neurochemicals vs T-S synapse density. $r$ value represents Pearson's correlation. Data from WT $n=12, z Q 175 n=15$, $\mathrm{zQ} 175: C K 2 \alpha^{\prime(+-)} \mathrm{n}=9$ corresponding to all three time points $(3,6$ and 12 months $)$ is shown.

Table 1. ANOVA results for neurochemical concentrations measured by ${ }^{\mathbf{1}} \mathrm{H}-\mathrm{MRS}$. Neurochemical concentrations in WT, zQ175, and zQ175:CK2 $\alpha^{\prime(+)}$ mice over time. Values represented as mean \pm SD. One-way ANOVA with Tukey-adjusted $p$-values for those <0.05. * indicates WT vs. zQ175, \# indicates WT vs. zQ175:CK2 $\alpha^{\prime(+/)}$, and * indicates zQ175 vs. zQ175:CK2a'(+/-).

Table 2. Excitatory synapse density ANOVA results. Mean synapse density (relative to WT) between genotypes and across time points. Error presented as \pm SD. One-way ANOVA with Tukey-adjusted p-values.

\section{Table 3. Correlation analyses between synapse number and metabolite} concentration. Pearson coefficient and unadjusted $p$-value calculated from correlation analyses between all neurochemicals and synapse \# (C-S and T-S correlations run separately). Holm-Šídák multiple comparison post-hoc test was run for C-S and T-S separately, represented by adjusted p-values. All ages and genotypes are pooled for 
each analysis corresponding to WT $n=12, z Q 175 n=15$ and $z Q 175: C K 2 \alpha^{\prime(+/)} n=9$ from all three time points (3, 6 and 12 months).

\section{REFERENCES}

Adanyeguh IM, Monin M-L, Rinaldi D, Freeman L, Durr A, Lehéricy S, Henry P-G, Mochel $F$ (2018) Expanded neurochemical profile in the early stage of Huntington disease using proton magnetic resonance spectroscopy. NMR Biomed 31.

Behrens PF, Franz P, Woodman B, Lindenberg KS, Landwehrmeyer GB (2002) Impaired glutamate transport and glutamate-glutamine cycling: downstream effects of the Huntington mutation. Brain 125:1908-1922.

Cepeda C, Wu N, André VM, Cummings DM, Levine MS (2007) The Corticostriatal Pathway in Huntington's Disease. Prog Neurobiol 81:253-271.

Deng YP, Wong T, Wan JY, Reiner A (2014) Differential loss of thalamostriatal and corticostriatal input to striatal projection neuron types prior to overt motor symptoms in the Q140 knock-in mouse model of Huntington's disease. Front Syst Neurosci 8:198.

Duarte JMN, Do KQ, Gruetter R (2014) Longitudinal neurochemical modifications in the aging mouse brain measured in vivo by $1 \mathrm{H}$ magnetic resonance spectroscopy. Neurobiol Aging 35:1660-1668.

Fan MMY, Raymond LA (2007) N-methyl-D-aspartate (NMDA) receptor function and excitotoxicity in Huntington's disease. Prog Neurobiol 81:272-293.

Finnema SJ, Nabulsi NB, Eid T, Detyniecki K, Lin SF, Chen MK, Dhaher R, Matuskey D, Baum E, Holden D, Spencer DD, Mercier J, Hannestad J, Huang Y, Carson RE (2016) Imaging synaptic density in the living human brain. Sci Transl Med 8:348ra96-348ra96.

Friedrich $\mathrm{J}$ et al. (2018) Antisense oligonucleotide-mediated ataxin-1 reduction prolongs survival in SCA1 mice and reveals disease-associated transcriptome profiles. JCl Insight 3.

Fujiyama F, Kuramoto E, Okamoto K, Hioki H, Furuta T, Zhou L, Nomura S, Kaneko T (2004) Presynaptic localization of an AMPA-type glutamate receptor in corticostriatal and thalamostriatal axon terminals. Eur J Neurosci 20:3322-3330.

Garwood M, DelaBarre L (2001) The Return of the Frequency Sweep: Designing Adiabatic Pulses for Contemporary NMR. J Magn Reson 153:155-177.

Gomez-Pastor R, Burchfiel ET, Neef DW, Jaeger AM, Cabiscol E, Mckinstry SU, Doss A, Aballay A, Lo DC, Akimov SS, Ross CA, Eroglu C, Thiele DJ (2017) Abnormal 
degradation of the neuronal stress-protective transcription factor HSF1 in Huntington's disease. Nat Commun 8.

Govindaraju V, Young K, Maudsley AA (2000) Proton NMR chemical shifts and coupling constants for brain metabolites. NMR Biomed 13:129-153.

Grachev ID, Apkarian AV (2001) Aging alters regional multichemical profile of the human brain: an in vivo1H-MRS study of young versus middle-aged subjects. J Neurochem 76:582-593.

Gruetter R, Tkác I (2000) Field Mapping Without Reference Scan Using Asymmetric Echo-Planar Techniques. Magn Reson Med 43:319-323.

Hassel B, Tessler S, Faull RLM, Emson PC (2008) Glutamate uptake is reduced in prefrontal cortex in Huntington's disease. Neurochem Res 33:232-237.

Heikkinen T, Lehtimäki K, Vartiainen N, Puoliväli J, Hendricks SJ, Glaser JR, Bradaia A, Wadel K, Touller C, Kontkanen O, Yrjänheikki JM, Buisson B, Howland D, Beaumont V, Munoz-Sanjuan I, Park LC (2012) Characterization of Neurophysiological and Behavioral Changes, MRI Brain Volumetry and $1 \mathrm{H}$ MRS in zQ175 Knock-In Mouse Model of Huntington's Disease Okazawa H, ed. PLoS One 7:e50717.

Hennig J, Nauerth A, Friedburg H (1986) RARE imaging: A fast imaging method for clinical MR. Magn Reson Med 3:823-833.

Hsu Y-T, Chang Y-G, Chern Y (2018) Insights into GABAAergic system alteration in Huntington's disease. R Soc Open Biol 8.

Huerta-Ocampo I, Mena-Segovia J, Bolam JP (2014) Convergence of cortical and thalamic input to direct and indirect pathway medium spiny neurons in the striatum. Brain Struct Funct 219:1787-1800.

Ippolito DM, Eroglu C (2010) Quantifying synapses: An immunocytochemistry-based assay to quantify synapse number. $J$ Vis Exp.

Joers JM, Deelchand DK, Lyu T, Emir UE, Hutter D, Gomez CM, Bushara KO, Eberly LE, Öz G (2018) Neurochemical abnormalities in premanifest and early spinocerebellar ataxias. Ann Neurol 83:816-829.

Kolodziejczyk K, Raymond LA (2016) Differential changes in thalamic and cortical excitatory synapses onto striatal spiny projection neurons in a Huntington disease mouse model. Neurobiol Dis 86:62-74.

Leavitt BR, Weir DW, Sturrock A (2011) Development of biomarkers for Huntington's disease. Lancet Neurol 10:573-590.

Liévens JC, Woodman B, Mahal A, Spasic-Boscovic O, Samuel D, Kerkerian-Le Goff L, 
Bates GP (2001) Impaired glutamate uptake in the R6 Huntington's disease transgenic mice. Neurobiol Dis 8:807-821.

Lizarbe B, Soares AF, Larsson S, Duarte JMN (2018) Neurochemical Modifications in the Hippocampus, Cortex and Hypothalamus of Mice Exposed to Long-Term HighFat Diet. Front Neurosci 12.

MacDonald ME et al. (1993) A novel gene containing a trinucleotide repeat that is expanded and unstable on Huntington's disease chromosomes. Cell 72:971-983.

Mckinstry SU, Karadeniz YB, Worthington AK, Hayrapetyan VY, Ozlu MI, Serafin-Molina K, Risher XWC, Ustunkaya T, Dragatsis I, Zeitlin XS, Yin HH, Eroglu C (2014) Huntingtin Is Required for Normal Excitatory Synapse Development in Cortical and Striatal Circuits. J Neurosci 34:9455-9472.

Menalled LB et al. (2012) Comprehensive Behavioral and Molecular Characterization of a New Knock-In Mouse Model of Huntington's Disease: zQ175. PLoS One 7:e49838.

Murray ME, Przybelski SA, Lesnick TG, Liesinger AM, Spychalla A, Zhang B, Gunter JL, Parisi JE, Boeve BF, Knopman DS, Petersen RC, Jack CR, Dickson DW, Kantarci K (2014) Early Alzheimer's disease neuropathology detected by proton MR spectroscopy. J Neurosci 34:16247-16255.

Öz G ed. (2016) Magnetic Resonance Spectroscopy of Degenerative Brain Diseases. Springer International Publishing.

Öz G, Iltis I, Hutter D, Thomas W, Bushara KO, Gomez CM (2011a) Distinct Neurochemical Profiles of Spinocerebellar Ataxias 1, 2, 6, and Cerebellar Multiple System Atrophy. Cerebellum 10:208-217.

Öz G, Kittelson E, Demirgoz D, Rainwater O, Eberly LE, Orr HT, Clark HB (2015) Assessing recovery from neurodegeneration in spinocerebellar ataxia 1: Comparison of in vivo magnetic resonance spectroscopy with motor testing, gene expression and histology. Neurobiol Dis 74:158-166.

Öz G, Nelson CD, Koski DM, Henry P-G, Marjanska M, Deelchand DK, Shanley R, Eberly LE, Orr HT, Clark HB (2010) Noninvasive detection of presymptomatic and progressive neurodegeneration in a mouse model of spinocerebellar ataxia type 1. J Neurosci 30:3831-3838.

Öz G, Vollmers ML, Nelson CD, Shanley R, Eberly LE, Orr HT, Clark HB (2011b) In vivo monitoring of recovery from neurodegeneration in conditional transgenic SCA1 mice. Exp Neurol 232:290-298.

Peng Q, Wu B, Jiang M, Jin J, Hou Z, Zheng J, Zhang J, Duan W (2016) Characterization of Behavioral, Neuropathological, Brain Metabolic and Key Molecular Changes in zQ175 Knock-In Mouse Model of Huntington's Disease. 


\section{PLoS One 11:e0148839.}

Pépin J, Francelle L, Carrillo-de Sauvage MA, de Longprez L, Gipchtein P, Cambon K, Valette J, Brouillet E, Flament J (2016) In vivo imaging of brain glutamate defects in a knock-in mouse model of Huntington's disease. Neuroimage 139:53-64.

Provencher SW (1993) Estimation of metabolite concentrations from localized in vivo proton NMR spectra. Magn Reson Med 30:672-679.

Raymond LA, André VM, Cepeda C, Gladding CM, Milnerwood AJ, Levine MS (2011) Pathophysiology of Huntington's disease: Time-dependent alterations in synaptic and receptor function. Neuroscience 198:252-273.

Rebholz H, Zhou M, Nairn AC, Greengard P, Flajolet M (2013) Selective Knockout of the Casein Kinase 2 in D1 Medium Spiny Neurons Controls Dopaminergic Function. Biol Psychiatry 74:113-121.

Reilmann R, Rolf LH, Lange HW (1995) Decreased plasma alanine and isoleucine in Huntington's disease. Acta Neurol Scand 91:222-224.

Reiner A, Albin RL, Anderson KD, D'Amato CJ, Penney JB, Young AB (1988) Differential loss of striatal projection neurons in Huntington disease. Proc Natl Acad Sci U S A 85:5733-5737.

Sánchez-Pernaute R, García-Segura JM, Del Barrio Alba A, Viaño J, De Yébenes JG (1999) Clinical correlation of striatal 1H MRS changes in Huntington's disease. Neurology 53:806-812.

Skotte NH, Andersen J V., Santos A, Aldana BI, Willert CW, Nørremølle A, Waagepetersen HS, Nielsen ML (2018) Integrative Characterization of the R6/2 Mouse Model of Huntington's Disease Reveals Dysfunctional Astrocyte Metabolism. Cell Rep 23:2211-2224.

Smith Y, Raju D, Nanda B, Pare J-F, Galvan A, Wichmann T (2009) The Thalamostriatal Systems: Anatomical and Functional Organization in Normal and Parkinsonian States. Brain Res Bull 78:60-68.

Solís-Maldonado M, Miró MP, Acuña Al, Covarrubias-Pinto A, Loaiza A, Mayorga G, Beltrán FA, Cepeda C, Levine MS, Concha II, Bátiz LF, Carrasco MA, Castro MA (2018) Altered lactate metabolism in Huntington's disease is dependent on GLUT3 expression. CNS Neurosci Ther 24:343-352.

Spokes EGS, Garrett NJ, Rossor MN, Iversen LL (1980) Distribution of GABA in postmortem brain tissue from control, psychotic and Huntington's chorea subjects. J Neurol Sci 48:303-313.

Sturrock A, Laule C, Decolongon J, Dar Santos R, Coleman AJ, Creighton S, Bechtel N, Reilmann R, Hayden MR, Tabrizi SJ, Mackay AL, Leavitt BR (2010) Magnetic 
resonance spectroscopy biomarkers in premanifest and early Huntington disease. Neurology 75:1702-1710.

Sturrock A, Laule C, Wyper K, Milner RA, Decolongon J, Santos RD, Coleman AJ, Carter K, Creighton S, Bechtel N, Bohlen S, Reilmann R, Johnson HJ, Hayden MR, Tabrizi SJ, Mackay AL, Leavitt BR, Library WO (2015) A Longitudinal Study of Magnetic Resonance Spectroscopy Huntington's Disease Biomarkers. Mov Disord 30.

Thomsen MB, Jacobsen J, Lillethorup TP, Schacht AC, Simonsen M, Romero-Ramos M, Brooks DJ, Landau AM (2021) In vivo imaging of synaptic SV2A protein density in healthy and striatal-lesioned rats with [11C]UCB-J PET. J Cereb Blood Flow Metab 41:819-830.

Tkác I (2008) Refinement of simulated basis set for LCModel analysis. In: 16th Annual Meeting ISMRM, pp 1624.

Tkác I, Dubinsky JM, Keene CD, Gruetter R, Low WC (2007) Neurochemical changes in Huntington R6/2 mouse striatum detected by in vivo1H NMR spectroscopy. J Neurochem 100:1397-1406.

Tkác I, Henry P-G, Zacharoff L, Wedel M, Gong W, Deelchand DK, Li T, Dubinsky JM (2012) Homeostatic Adaptations in Brain Energy Metabolism in Mouse Models of Huntington Disease: J Cereb Blood Flow Metab 32:1977-1988.

Tkác I, Starčuk Z, Choi I-Y, Gruetter R (1999) In Vivo 1 H NMR Spectroscopy of Rat Brain at 1 ms Echo Time. Magn Reson Med 41:649-656.

Underwood BR, Broadhurst D, Dunn WB, Ellis DI, Michell AW, Vacher C, Mosedale DE, Kell DB, Barker RA, Grainger DJ, Rubinsztein DC (2006) Huntington disease patients and transgenic mice have similar pro-catabolic serum metabolite profiles. Brain 129:877-886.

Unschuld PG, Joel SE, Liu X, Shanahan M, Margolis RL, Biglan KM, Bassett SS, Schretlen DJ, Redgrave GW, van Zijl PCM, Pekar JJ, Ross CA (2012) Impaired cortico-striatal functional connectivity in prodromal Huntington's Disease. Neurosci Lett 514:204-209.

Yu D et al. (2020) CK2 alpha prime and alpha-synuclein pathogenic functional interaction mediates inflammation and transcriptional dysregulation in Huntington's disease. bioRxiv:2020.10.29.359380.

Zhang W, Gu G-J, Zhang Q, Liu J-H, Zhang B, Guo Y, Wang M-Y, Gong Q-Y, Xu J-R (2017) NSCs promote hippocampal neurogenesis, metabolic changes and synaptogenesis in APP/PS1 transgenic mice. Hippocampus 27:1250-1263. 
Table 1. ANOVA results for neurochemical concentrations measured by ${ }^{1} \mathrm{H}-\mathrm{MRS}$

\begin{tabular}{|c|c|c|c|c|c|c|c|c|c|c|c|c|}
\hline \multicolumn{13}{|c|}{$\mu \mathrm{mol} / \mathrm{g}($ mean $\pm \mathrm{SD})$} \\
\hline & \multicolumn{4}{|c|}{3 Months } & \multicolumn{4}{|c|}{6 Months } & \multicolumn{4}{|c|}{12 Months } \\
\hline Metabolite & WT & zQ175 & zQ175:CK2 $\alpha^{3(+/-)}$ & $p$-value & WT & zQ175 & zQ175:CK2a ${ }^{\prime(++/)}$ & $p$-value & WT & zQ175 & zQ175:CK2 $\alpha^{3(+/-)}$ & $p$-value \\
\hline Ala & $1.64 \pm 0.31$ & $1.5 \pm 0.29$ & $1.5 \pm 0.37$ & ns & $1.21 \pm 0.24$ & $0.89 \pm 0.21$ & $1.06 \pm 0.22$ & ${ }^{* *} 0.0071$ & $0.97 \pm 0.33$ & $0.81 \pm 0.32$ & $0.90 \pm 0.09$ & ns \\
\hline Asc & $1.33 \pm 0.27$ & $1.32 \pm 0.20$ & $1.28 \pm 0.30$ & ns & $1.30 \pm 0.26$ & $1.44 \pm 0.36$ & $1.52 \pm 0.26$ & ns & $1.10 \pm 0.24$ & $1.45 \pm 0.44$ & $1.74 \pm 0.45$ & \#0.0389 \\
\hline Asp & $\mathrm{n} / \mathrm{a}$ & $1.52 \pm 0.46$ & $1.39 \pm 0.28$ & ns & $1.56 \pm 0.49$ & $1.46 \pm 0.41$ & $1.57 \pm 0.38$ & ns & $\mathrm{n} / \mathrm{a}$ & $1.60 \pm 0.31$ & $\mathrm{n} / \mathrm{a}$ & ns \\
\hline GABA & $2.59 \pm 0.41$ & $2.69 \pm 0.26$ & $2.74 \pm 0.30$ & ns & $2.49 \pm 0.26$ & $2.59 \pm 0.27$ & $2.59 \pm 0.28$ & ns & $2.48 \pm 0.14$ & $2.40 \pm 0.29$ & $2.43 \pm 0.37$ & ns \\
\hline Glc & $2.49 \pm 1.04$ & $\mathrm{n} / \mathrm{a}$ & $2.24 \pm 0.89$ & ns & $2.68 \pm 0.60$ & $2.87 \pm 0.96$ & $1.72 \pm 0.63$ & $\begin{array}{c}0.0228 \\
0.0019\end{array}$ & $\mathrm{n} / \mathrm{a}$ & $\mathrm{n} / \mathrm{a}$ & $\mathrm{n} / \mathrm{a}$ & ns \\
\hline GIn & $2.95 \pm 0.20$ & $3.16 \pm 0.15$ & $2.87 \pm 0.26$ & $\begin{array}{l}{ }^{*} 0.0259 \\
\diamond \diamond \bullet \\
0.0009\end{array}$ & $3.06 \pm 0.10$ & $3.36 \pm 0.24$ & $3.21 \pm 0.27$ & * 0.0143 & $3.46 \pm 0.25$ & $4.12 \pm 0.35$ & $3.79 \pm 0.26$ & ${ }^{* *} 0.0031$ \\
\hline Glu & $6.86 \pm 0.51$ & $7.07 \pm 0.40$ & $6.82 \pm 0.45$ & ns & $7.01 \pm 0.54$ & $7.11 \pm 0.30$ & $7.04 \pm 0.51$ & ns & $7.24 \pm 0.46$ & $7.06 \pm 0.60$ & $7.15 \pm 0.23$ & ns \\
\hline GSH & $0.98 \pm 0.08$ & $0.99 \pm 0.11$ & $1.04 \pm 0.12$ & ns & $1.11 \pm 0.16$ & $1.00 \pm 0.16$ & $0.96 \pm 0.13$ & ns & $0.88 \pm 0.10$ & $0.78 \pm 0.27$ & $0.87 \pm 0.15$ & ns \\
\hline Gly & $1.01 \pm 0.17$ & $0.94 \pm 0.24$ & $1.04 \pm 0.13$ & ns & $1.00 \pm 0.15$ & $1.12 \pm 0.17$ & $1.09 \pm 0.25$ & ns & $0.84 \pm 0.27$ & $1.05 \pm 0.32$ & $1.11 \pm 0.25$ & ns \\
\hline Ins & $3.70 \pm 0.36$ & $4.10 \pm 0.52$ & $3.95 \pm 0.41$ & ns & $3.72 \pm 0.32$ & $4.24 \pm 0.49$ & $4.16 \pm 0.24$ & $\begin{array}{l}{ }^{* *} 0.0076 \\
\# 0.0234\end{array}$ & $3.41 \pm 0.38$ & $3.89 \pm 0.48$ & $3.98 \pm 0.39$ & ns \\
\hline Lac & $6.54 \pm 0.96$ & $6.21 \pm 0.86$ & $6.48 \pm 1.00$ & ns & $5.56 \pm 1.36$ & $5.02 \pm 0.93$ & $5.60 \pm 0.69$ & ns & $5.50 \pm 1.63$ & $4.76 \pm 1.46$ & $5.06 \pm 0.85$ & ns \\
\hline Mac & $\begin{array}{c}128.80 \pm \\
5.18\end{array}$ & $127.31 \pm 4.54$ & $125.85 \pm 4.01$ & ns & $122.73 \pm 4.60$ & $127.41 \pm 6.41$ & $125.43 \pm 6.21$ & ns & $126.68 \pm 4.05$ & $124.57 \pm 2.37$ & $124.71 \pm 5.07$ & ns \\
\hline NAA & $6.15 \pm 0.19$ & $6.11 \pm 0.18$ & $6.05 \pm 0.23$ & ns & $6.13 \pm 0.16$ & $6.13 \pm 0.21$ & $6.01 \pm 0.21$ & ns & $6.36 \pm 0.23$ & $6.10 \pm 0.31$ & $6.03 \pm 0.41$ & ns \\
\hline PE & $2.64 \pm 0.42$ & $2.60 \pm 0.41$ & $2.54 \pm 0.23$ & ns & $2.61 \pm 0.34$ & $2.13 \pm 0.42$ & $2.17 \pm 0.30$ & $\begin{array}{l}* 0.0129 \\
\# 0.0218\end{array}$ & $2.25 \pm 0.21$ & $2.17 \pm 0.15$ & $2.04 \pm 0.30$ & ns \\
\hline Tau & $13.47 \pm 1.14$ & $13.02 \pm 0.79$ & $13.01 \pm 0.73$ & ns & $12.87 \pm 0.42$ & $12.34 \pm 0.92$ & $12.14 \pm 0.60$ & ns & $13.08 \pm 1.16$ & $12.31 \pm 1.27$ & $12.56 \pm 0.76$ & ns \\
\hline tCho & $1.47 \pm 0.13$ & $1.4 \pm 0.11$ & $1.32 \pm 0.08$ & \#\#0.0027 & $1.54 \pm 0.12$ & $1.39 \pm 0.14$ & $1.31 \pm 0.10$ & $\begin{array}{c}* 0.0242 \\
\# \# 0.0005\end{array}$ & $1.51 \pm 0.04$ & $1.32 \pm 0.16$ & $1.34 \pm 0.09$ & ${ }^{*} 0.0354$ \\
\hline $\mathrm{tCr}$ & $7.54 \pm 0.22$ & $7.62 \pm 0.19$ & $7.55 \pm 0.20$ & ns & $7.71 \pm 0.35$ & $8.35 \pm 0.25$ & $8.17 \pm 0.24$ & $\begin{array}{c}* * * *<0.0001 \\
\# \# 0.0015\end{array}$ & $7.54 \pm 0.32$ & $8.48 \pm 0.63$ & $8.52 \pm 0.31$ & $\begin{array}{r}{ }^{* *} 0.0076 \\
\# \# 0.0069\end{array}$ \\
\hline $\begin{array}{r}\text { tNAA } \\
(N A A+N A A G)\end{array}$ & $6.39 \pm 0.22$ & $6.34 \pm 0.18$ & $6.32 \pm 0.27$ & ns & $6.39 \pm 0.18$ & $6.34 \pm 0.24$ & $6.26 \pm 0.28$ & ns & $6.62 \pm 0.28$ & $6.38 \pm 0.28$ & $6.26 \pm 0.43$ & ns \\
\hline Glc+Tau & $15.76 \pm 2.16$ & $15.41 \pm 1.48$ & $15.25 \pm 1.22$ & ns & $15.25 \pm 0.93$ & $15.22 \pm 1.63$ & $13.86 \pm 0.88$ & $\begin{array}{l}\# 0.0340 \\
>0.0239\end{array}$ & $14.78 \pm 1.98$ & $14.60 \pm 2.31$ & $14.00 \pm 1.48$ & ns \\
\hline $\mathrm{tNAA} / \mathrm{tCr}$ & $0.85 \pm 0.03$ & $0.83 \pm 0.03$ & $0.84 \pm 0.03$ & ns & $0.83 \pm 0.04$ & $0.76 \pm 0.03$ & $0.77 \pm 0.03$ & $\begin{array}{l}* * * 0.0002 \\
\# \# 0.0005\end{array}$ & $0.88 \pm 0.04$ & $0.75 \pm 0.06$ & $0.74 \pm 0.06$ & $\begin{array}{l}{ }^{* *} 0.0047 \\
\# \# 0.0018\end{array}$ \\
\hline
\end{tabular}


Table 2. Excitatory synapse density ANOVA results.

\begin{tabular}{|c|c|c|c|c|c|c|}
\hline \multicolumn{7}{|c|}{ C-S Synapses } \\
\hline & \multicolumn{2}{|c|}{3 months } & \multicolumn{2}{|c|}{6 Months } & \multicolumn{2}{|c|}{12 Months } \\
\hline & $\begin{array}{c}\text { Mean } \\
(\% \text { of WT) }\end{array}$ & $\begin{array}{l}\text { Tukey- } \\
\text { Adjusted } \\
\text { p-value }\end{array}$ & $\begin{array}{c}\text { Mean } \\
\text { (\% of WT) }\end{array}$ & $\begin{array}{l}\text { Tukey- } \\
\text { Adjusted } \\
\text { p-value }\end{array}$ & $\begin{array}{c}\text { Mean } \\
(\% \text { of WT) }\end{array}$ & $\begin{array}{l}\text { Tukey- } \\
\text { Adjusted } \\
\text { p-value }\end{array}$ \\
\hline WT vs zQ175 & $\begin{array}{c}100.00 \pm 32.83 \\
\text { vs } \\
114.4 \pm 24.68\end{array}$ & 0.5769 & $\begin{array}{c}100.00 \pm 22.13 \\
\text { Vs } \\
85.61 \pm 21.01\end{array}$ & 0.1976 & $\begin{array}{c}100.00 \pm 30.19 \\
\text { Vs } \\
59.35 \pm 2.073\end{array}$ & $<0.0001$ \\
\hline $\begin{array}{c}\text { WT vs } \\
\text { zQ175:CK2 } \alpha^{\prime(+/)}\end{array}$ & $\begin{array}{c}100.00 \pm 32.83 \\
\text { vs } \\
135.8 \pm 36.17\end{array}$ & 0.0031 & $\begin{array}{c}100.00 \pm 22.13 \\
\text { vs } \\
83.14 \pm 16.39\end{array}$ & 0.0425 & $\begin{array}{c}100.00 \pm 30.19 \\
\text { vs } \\
69.31 \pm 22.19\end{array}$ & $<0.0001$ \\
\hline $\begin{array}{c}\text { zQ175 vs } \\
\text { zQ175:CK2 } \alpha^{\prime(+/-)}\end{array}$ & $\begin{array}{c}114.4 \pm 24.68 \\
\text { vs } \\
135.8 \pm 36.17\end{array}$ & 0.0628 & $\begin{array}{c}85.61 \pm 21.01 \\
\text { vs } \\
83.14 \pm 16.39\end{array}$ & 0.7661 & $\begin{array}{c}59.35 \pm 2.073 \\
\text { vs } \\
69.31 \pm 22.19\end{array}$ & 0.4883 \\
\hline \multicolumn{7}{|c|}{ T-S Synapses } \\
\hline & \multicolumn{2}{|c|}{3 months } & \multicolumn{2}{|c|}{6 Months } & \multicolumn{2}{|c|}{12 Months } \\
\hline & $\begin{array}{c}\text { Mean } \\
(\% \text { of WT) }\end{array}$ & $\begin{array}{l}\text { Tukey- } \\
\text { Adjusted } \\
\text { p-value }\end{array}$ & $\begin{array}{c}\text { Mean } \\
(\% \text { of WT) }\end{array}$ & $\begin{array}{l}\text { Tukey- } \\
\text { Adjusted } \\
\text { p-value }\end{array}$ & $\begin{array}{c}\text { Mean } \\
(\% \text { of WT) }\end{array}$ & $\begin{array}{l}\text { Tukey- } \\
\text { Adjusted } \\
\text { p-value }\end{array}$ \\
\hline WT vs zQ175 & $\begin{array}{c}100.00 \pm 16.01 \\
\text { vs } \\
79.61 \pm 16.02\end{array}$ & 0.0134 & $\begin{array}{c}100.00 \pm 32.97 \\
\text { vs } \\
62.17 \pm 35.45\end{array}$ & 0.013 & $\begin{array}{c}100.00 \pm 30.23 \\
\text { vs } \\
72.73 \pm 22.58\end{array}$ & 0.0062 \\
\hline $\begin{array}{c}\text { WT vs } \\
z Q 175: C K 2 \alpha^{\prime(+/-)}\end{array}$ & $\begin{array}{c}100.00 \pm 16.01 \\
\text { vs } \\
101.0 \pm 10.54\end{array}$ & 0.9778 & $\begin{array}{c}100.00 \pm 32.97 \\
\text { vs } \\
108.0 \pm 58.73\end{array}$ & 0.4771 & $\begin{array}{c}100.00 \pm 30.23 \\
\text { vs } \\
88.32 \pm 65.25\end{array}$ & 0.5932 \\
\hline $\begin{array}{c}\text { zQ175 vs } \\
\text { zQ175:CK2 } \alpha^{\prime(+/-)}\end{array}$ & $\begin{array}{c}79.61 \pm 16.02 \\
\text { Vs } \\
101.0 \pm 10.54\end{array}$ & 0.0083 & $\begin{array}{c}62.17 \pm 35.45 \\
\text { vs } \\
108.0 \pm 58.73\end{array}$ & 0.0004 & $\begin{array}{c}72.73 \pm 22.58 \\
\text { vs } \\
88.32 \pm 65.25\end{array}$ & 0.2901 \\
\hline
\end{tabular}


Table 3. Correlation analyses between synapse number and metabolite concentration

\begin{tabular}{|c|c|c|c|c|c|c|}
\hline \multirow[b]{2}{*}{ Metabolite } & \multicolumn{3}{|c|}{ T-S Synapse \# } & \multicolumn{3}{|c|}{ C-S Synapse \# } \\
\hline & Pearson's r & $\begin{array}{l}\text { Unadjusted } \\
\text { p-value }\end{array}$ & $\begin{array}{l}\text { Adjusted } \\
\text { p-value }\end{array}$ & Pearson's $r$ & $\begin{array}{c}\text { Unadjusted } \\
\text { p-value }\end{array}$ & $\begin{array}{c}\text { Adjusted } \\
p \text {-value }\end{array}$ \\
\hline Ala & 0.3944 & 0.0173 & 0.2698 & -0.07708 & 0.6648 & 0.9969 \\
\hline Asc & 0.1385 & 0.4206 & 0.9873 & -0.1922 & 0.2762 & 0.9850 \\
\hline Asp & -0.2742 & 0.1055 & 0.7476 & 0.1269 & 0.4745 & 0.9969 \\
\hline GABA & -0.1917 & 0.2627 & 0.9525 & 0.5867 & 0.0003 & 0.0060 \\
\hline Glc & -0.1342 & 0.4351 & 0.9873 & 0.2246 & 0.2015 & 0.9727 \\
\hline GIn & -0.01227 & 0.9434 & 0.9879 & -0.346 & 0.045 & 0.5831 \\
\hline Glu & -0.2922 & 0.0838 & 0.7305 & 0.09244 & 0.6031 & 0.9969 \\
\hline GSH & -0.1328 & 0.4401 & 0.9873 & 0.2216 & 0.2078 & 0.9727 \\
\hline Gly & -0.2781 & 0.1005 & 0.7476 & 0.1223 & 0.4907 & 0.9969 \\
\hline Ins & -0.2922 & 0.0837 & 0.7305 & 0.08881 & 0.6174 & 0.9969 \\
\hline Lac & 0.3995 & 0.0158 & 0.2698 & -0.2056 & 0.2435 & 0.9799 \\
\hline Mac & 0.1277 & 0.4579 & 0.9873 & 0.1108 & 0.5328 & 0.9969 \\
\hline NAA & 0.02972 & 0.8634 & 0.9879 & 0.1599 & 0.3662 & 0.9934 \\
\hline PE & 0.4 & 0.0156 & 0.2698 & -0.04997 & 0.779 & 0.9969 \\
\hline Tau & 0.2474 & 0.1458 & 0.8233 & 0.1849 & 0.2951 & 0.9850 \\
\hline tCho & -0.1638 & 0.3399 & 0.9762 & 0.3392 & 0.0497 & 0.6005 \\
\hline $\mathrm{tCr}$ & -0.3383 & 0.0436 & 0.5100 & -0.1056 & 0.5523 & 0.9969 \\
\hline tNAA (NAA+NAAG) & 0.1364 & 0.4278 & 0.9873 & 0.07763 & 0.6626 & 0.9969 \\
\hline Glc+Tau & 0.05032 & 0.7707 & 0.9879 & 0.2565 & 0.1431 & 0.9276 \\
\hline $\mathrm{tNAA} / \mathrm{tCr}$ & 0.3509 & 0.0359 & 0.4629 & 0.1401 & 0.4295 & 0.9963 \\
\hline
\end{tabular}


MRS Scan

WT: $n=13$

zQ175: $\mathrm{n}=16$

$z Q 175: C K 2 \alpha^{3}(+-): n=16$

Synapse Density

WT: $n=3$

zQ175: $\mathrm{n}=3$

zQ175:CK2 $\alpha^{\prime(+(-):} \mathrm{n}=3$
MRS Scan

WT: $\mathrm{n}=9$

zQ175: $n=12$

zQ175:CK2 $\alpha^{\prime(+/):} \mathrm{n}=13$

Synapse Density

WT: $n=4$

zQ175: $\mathrm{n}=4$

zQ175:CK2 $\alpha^{\prime(+/)}: \mathrm{n}=4$
MRS Scan

WT: $\mathrm{n}=5$

zQ175: $\mathrm{n}=8$

zQ175:CK2 $\alpha^{\prime(+/)}: \mathrm{n}=7$

Synapse Density

WT: $n=5$

zQ175: $\mathrm{n}=8$

zQ175:CK2 $\alpha^{\prime(+/)}: \mathrm{n}=3$
3 Months

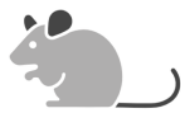

B)

MRS Voxel

(Sagittal View)

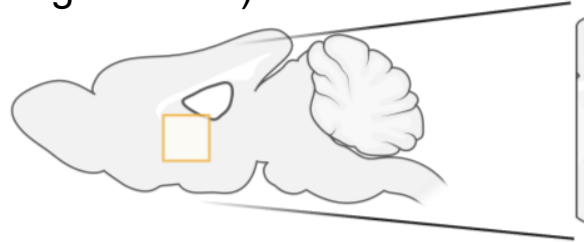

\section{Months}

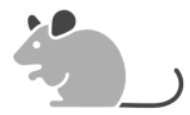

\section{Months}

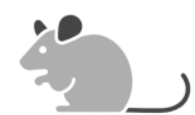

D) Synapse Density

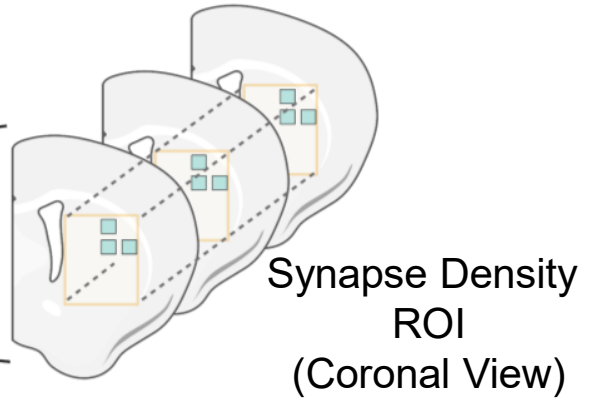

T-S

C-S

Synapse Synapse

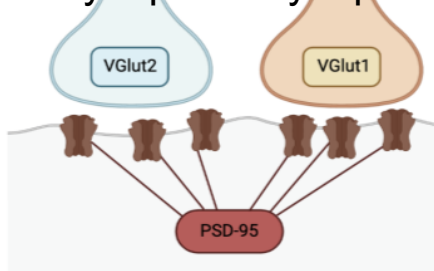

C) In vivo ${ }^{1} \mathrm{H}-\mathrm{MRS}$
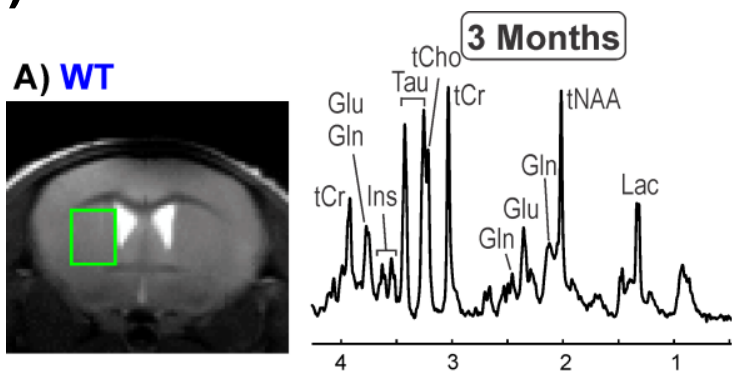

B) zQ175
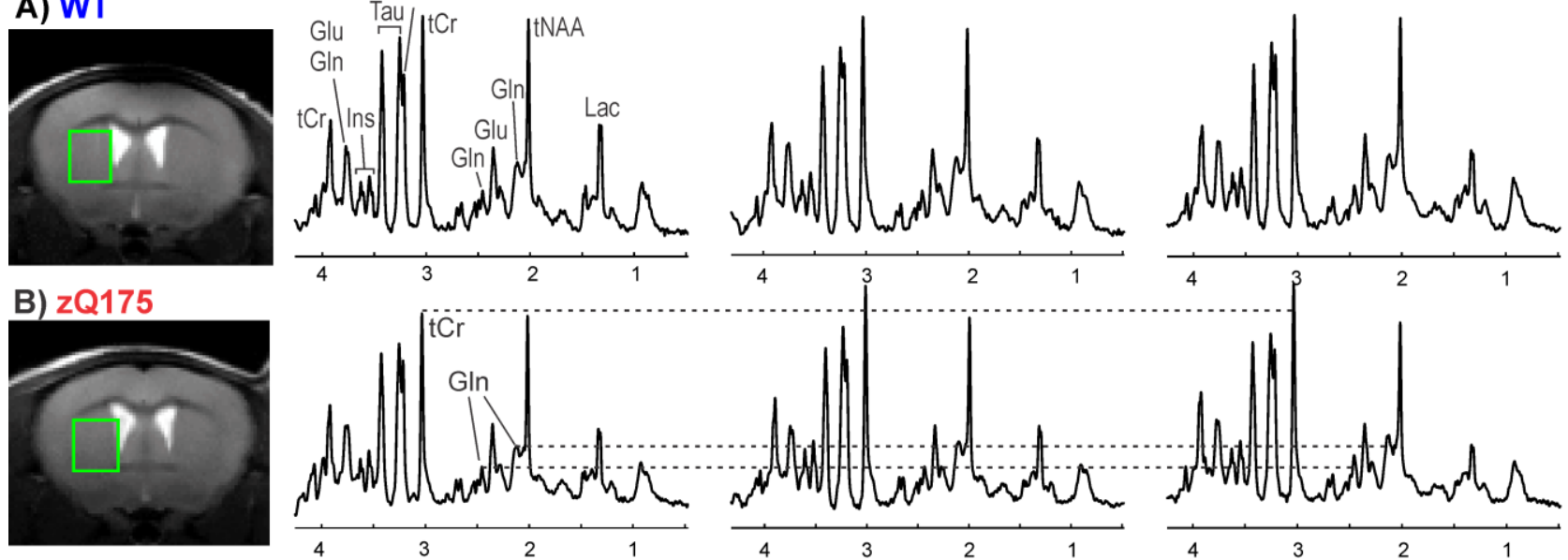

C) zQ175:CK2 $\alpha^{3(+/-)}$
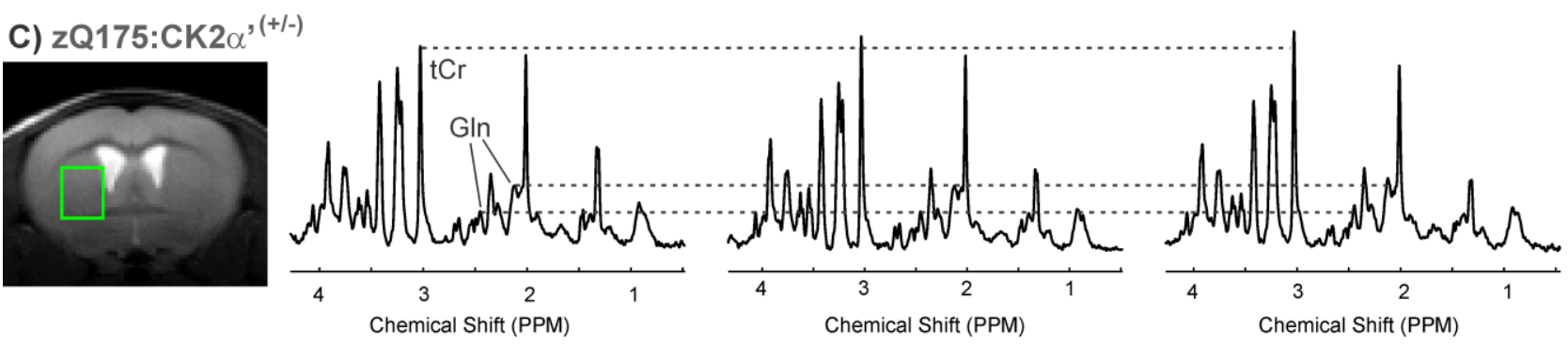
A)

Ala

B)

Asc
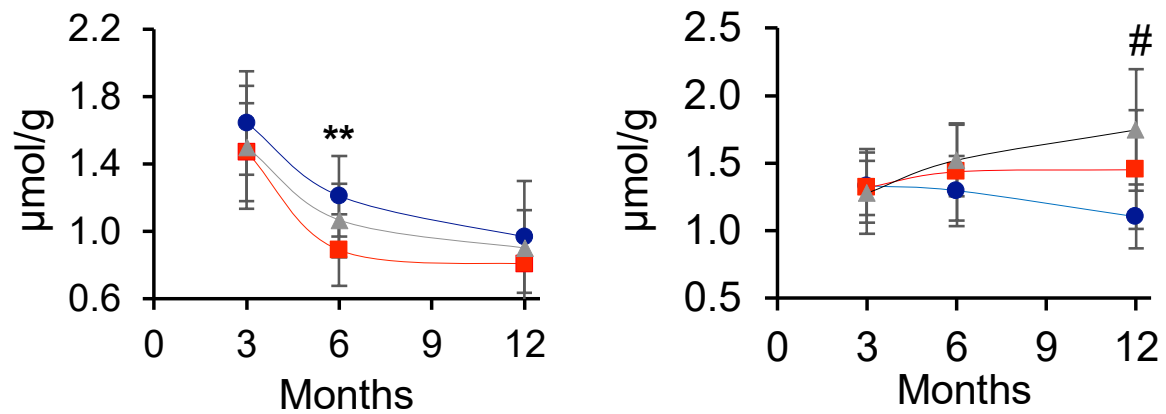

C)

PE

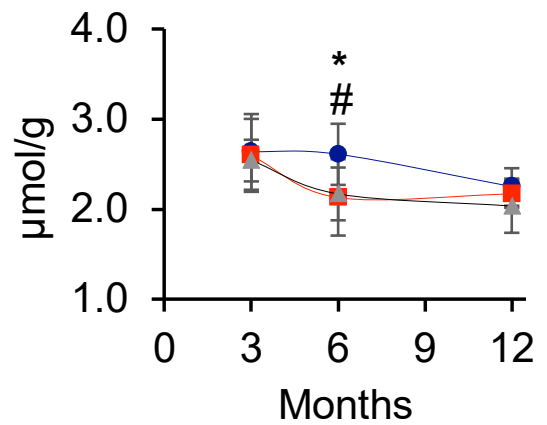

D)

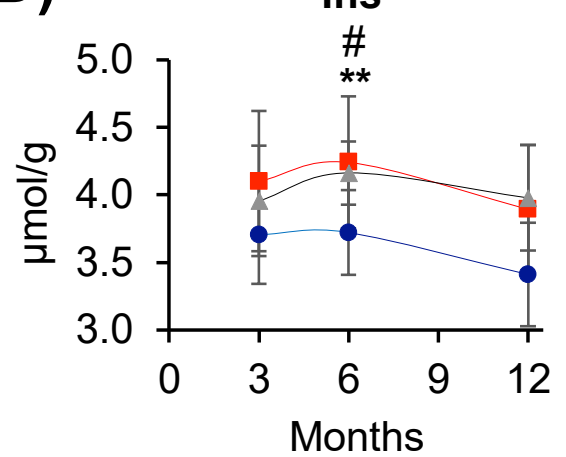

E)

F)

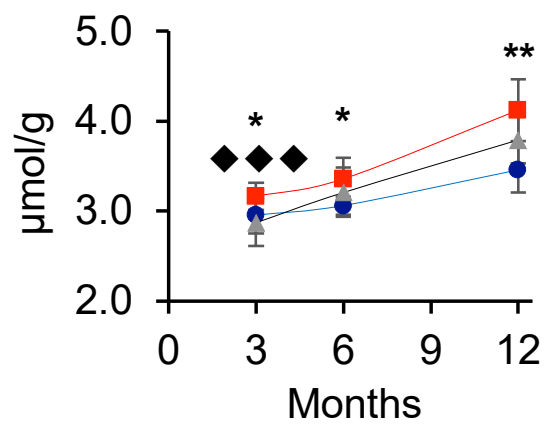

G)

tCho

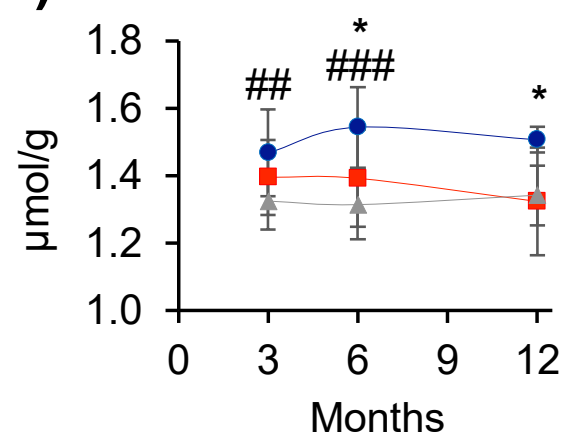

H) $\quad$ tNAA/tCr
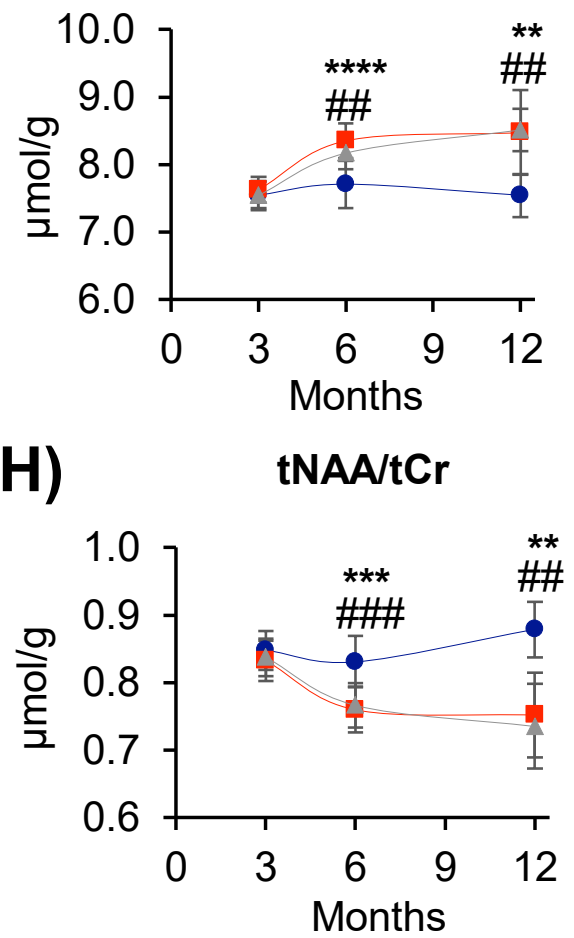

- WT $\square$ zQ175 $\Delta$ zQ175:CK2 $\alpha^{\prime(+)-)}$ 
A)
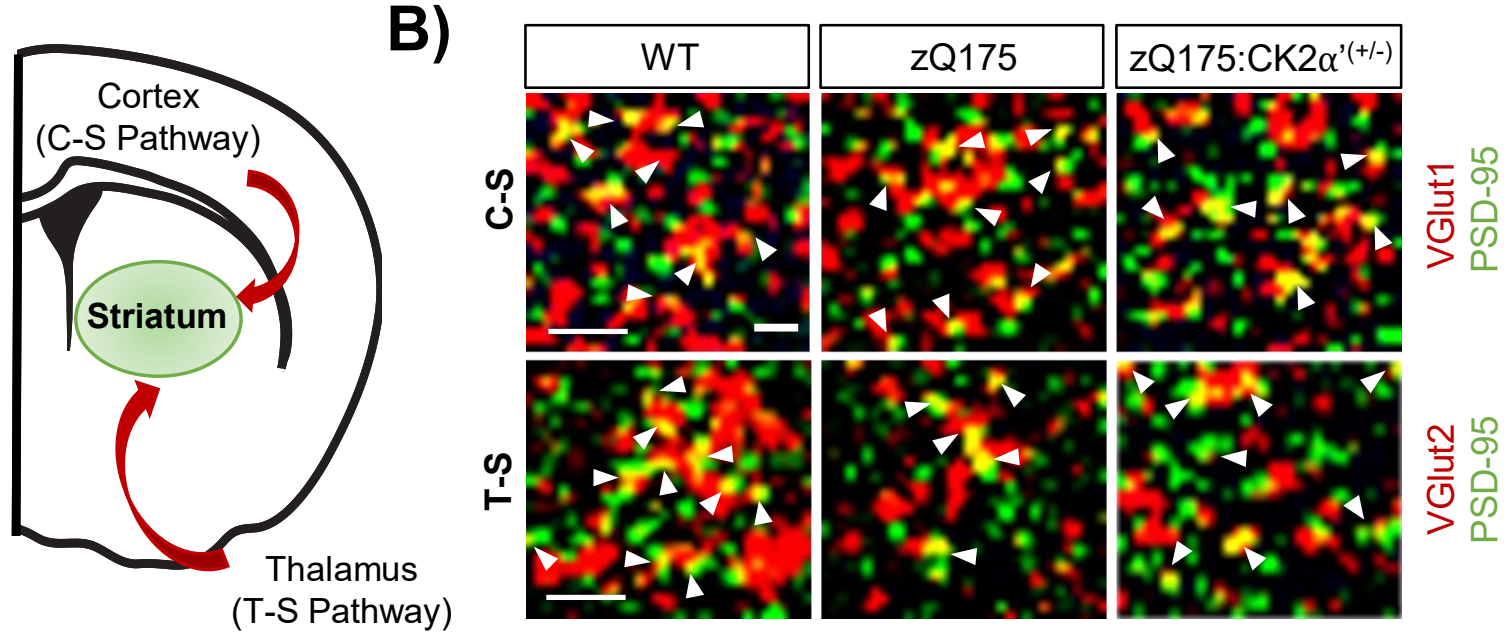

C)

3 Months

6 Months

12 Months
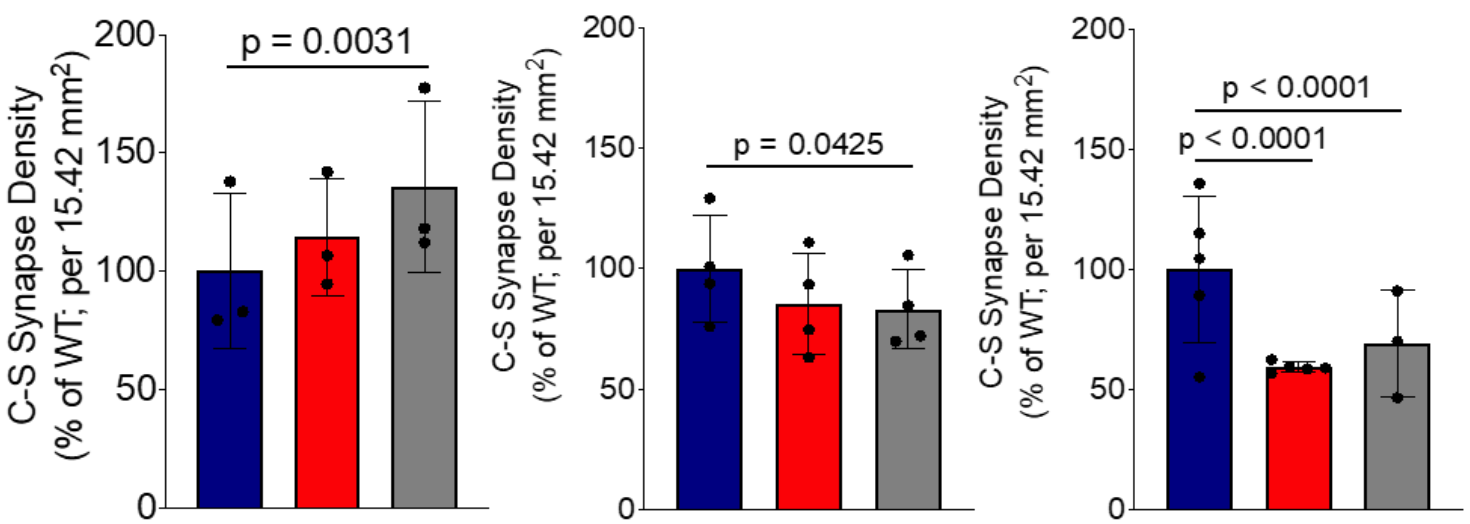

D)
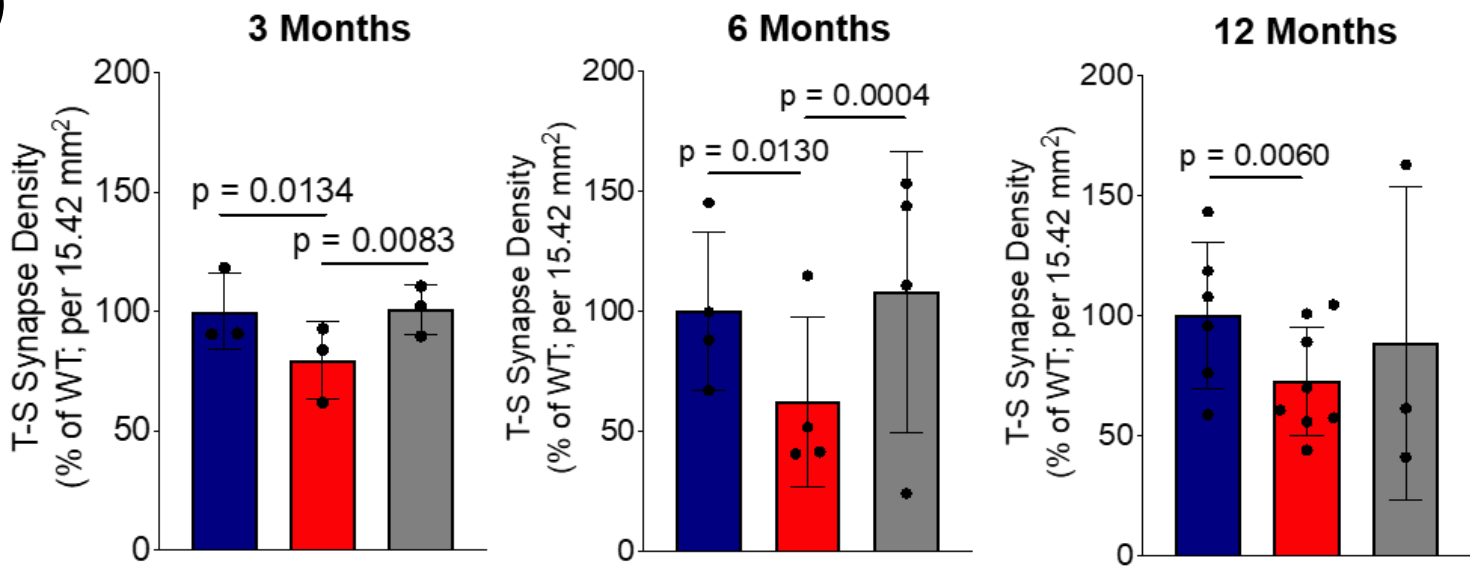

$\square$ WT $\square$ zQ175 $\square$ zQ175:CK2 $\alpha^{\prime(+/-)}$ 
A)

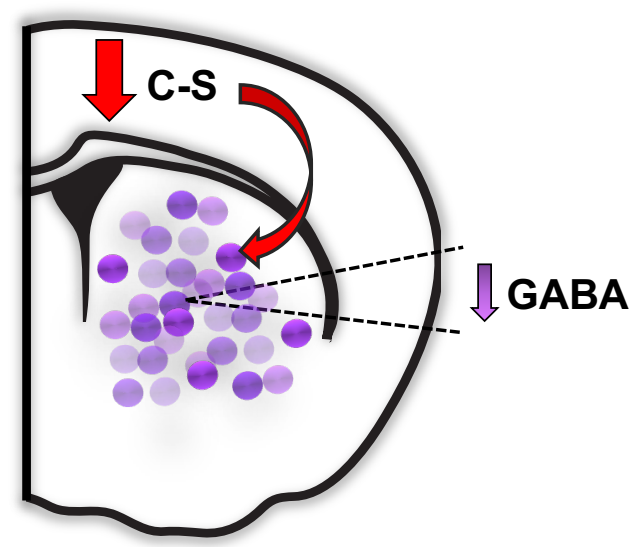

C)

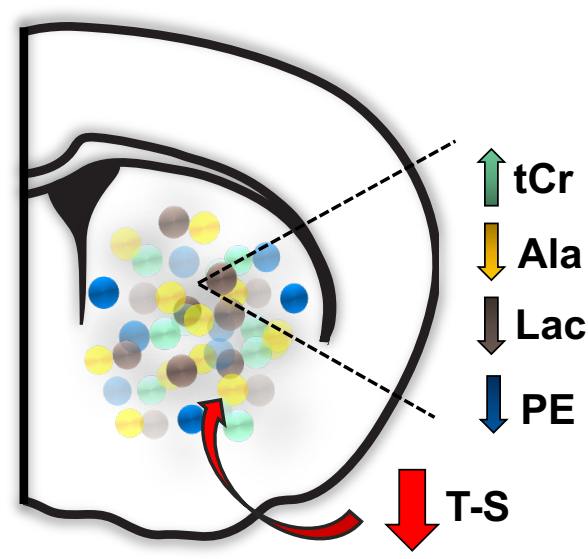

E)

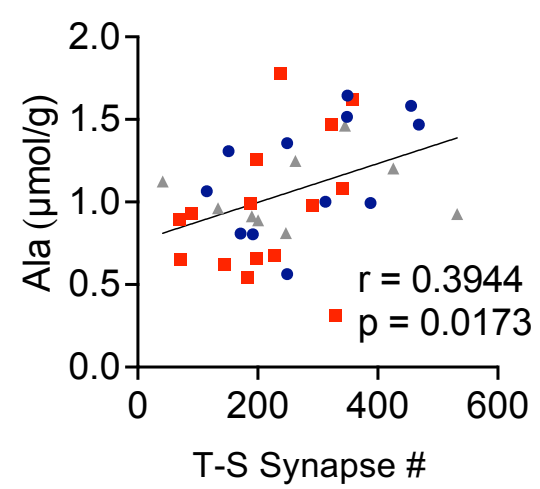

B)

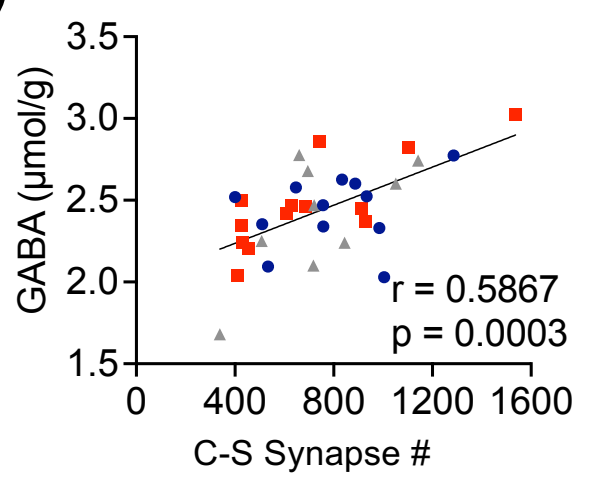

D)

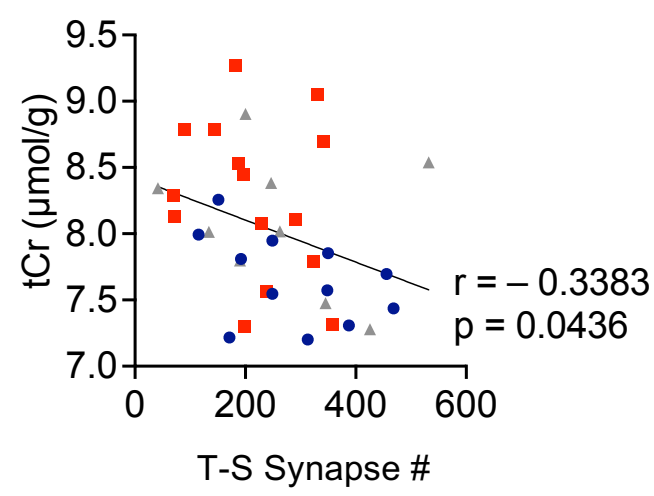

F)

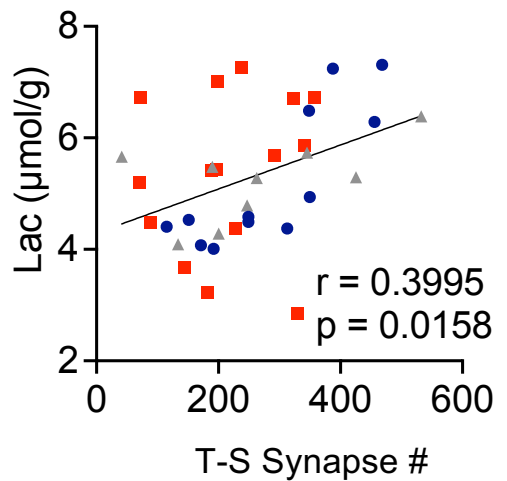

G)

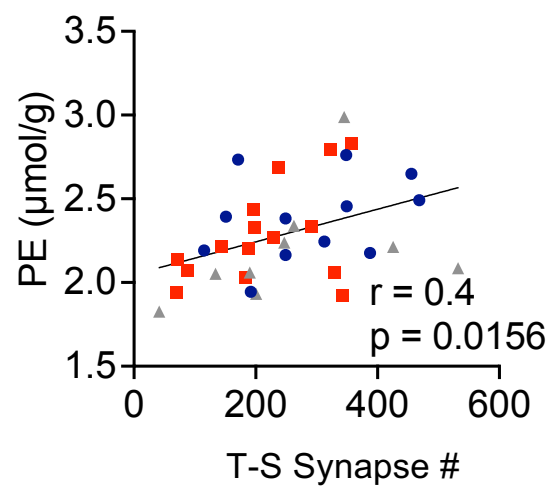

